\title{
SAN ISIDRO, CUNA DE LA REVOLUCIÓN MEXICANA. LOS INICIOS DEL MOVIMIENTO ARMADO DE I9IO EN CHIHUAHUA
}

\section{VÍCTOR OROZCO 1}

"En materia de interés público, es delito ocultar la verdad y en materia de virtud, es inmoral temerla".

Holbach

El día 19 de noviembre, en el pueblo de San Isidro, distrito de Guerrero, del Estado de Chihuahua, se congregó un grupo de ciudadanos valientes y desinteresados, que desde aquel instante se olvidaron de sus familias y de sus intereses para ofrendar sus vidas en aras de verdaderos principios, poniéndolo todo al servicio de una causa en que fincaban grandes esperanzas de mejoramiento nacional, sin planes aviesos ni cálculos egoístas.

Estos hombres, días después, casi en su totalidad quedaron tendidos en los campos de batalla, bien merecen que registremos sus nombres..."

Juan Gualberto Amaya, 1946

1 Maestro Emérito de la Universidad Autónoma de Ciudad Juárez, México. Correo electrónico: vorozco@uacj.mx 


\section{RESUMEN}

I as revoluciones o conmociones sociales que han dado lugar a nuevos países, nuevas formas de organización o de sistemas sociales, han reclamado desde siempre un lugar, una población, desde la cual comenzaron a desplegarse para involucrar a conglomerados, grupos, sectores de otras regiones y ciudades. Se les ha considerado cunas de estos movimientos. En el caso de la Revolución Mexicana de 1910 varias entidades y pueblos reclaman este título honorífico. Con base en un criterio de objetividad, para discernir cuál población acredita el mérito, se hace un recorrido puntual de hechos ocurridos en noviembre de 1910, para arribar a la conclusión de que es el pueblo de San Isidro, en el municipio de Guerrero, Chihuahua, al que debe considerarse Cuna de la Revolución de 1910.

Palabras clave: Revolución Mexicana, cuna, San Isidro, Chihuahua, Municipio de Guerrero, Cuchillo Parado.

\section{ABSTRACT}

The revolutions or social upheavals that have given rise to new countries, new forms of organization or social systems, have always claimed a place, a population, from which they began to deploy to involve conglomerates, groups, sectors from other regions and cities. They have been considered cradles of these movements. In the case of the Mexican Revolution of 1910 several entities and peoples claim this honorary title. Based on a criterion of objectivity, in order to discern which population credits the merit, a punctual tour of events occurred in november 1910 is made, to arrive at the conclusion that it is the town of San Isidro, in the municipality of Guerrero, Chihuahua, which must be considered the cradle of the 1910 revolution.

Keywords: Mexican Revolution, cradle, San Isidro, Chihuahua, Municipio de Guerrero, Cuchillo Parado. 


\section{LA CUESTIÓN: ¿POR QUÉ CUNA DE LA REVOLUCIÓN?}

Todos los pueblos del mundo buscan establecer los orígenes de aquellos hechos históricos considerados de mayor relevancia en su devenir. De igual manera, a procesos políticos, culturales o económicos que han traído como consecuencia transformaciones profundas en el mundo se les ha atribuido una cuna o una génesis. En el último sentido, por ejemplo, es común escuchar que Grecia es la cuna de la filosofía o de la civilización occidental, que Florencia es la cuna del Renacimiento, que Inglaterra es la cuna de la revolución industrial, etcétera.

Desde el primer ángulo, las revoluciones o conmociones sociales que han dado lugar a nuevos países, nuevas formas de organización o de sistemas sociales, han reclamado desde siempre un lugar, una población desde la cual comenzaron a desplegarse para involucrar a conglomerados, grupos, sectores de otras regiones y ciudades. Son conocidos los ejemplos de la revolución americana, que tiene como cuna a la población de Concord, en el estado de Massachusetts, sitio donde se produjo la primera confrontación armada entre los colonos insurrectos y las tropas inglesas. También, a Santiago de Cuba se le llama la cuna de la revolución cubana por los enfrentamientos que allí tuvieron lugar y con los cuales dio comienzo la gesta transformadora en la isla caribeña, culminada el 1 de enero de 1959. A la ciudad de San Petersburgo o Petrogrado, se le nombra cuna de la revolución rusa, pues allí también se desplegaron los primeros encuentros entre los destacamentos de revolucionarios y las fuerzas del antiguo régimen. En nuestro país, al antiguo pueblo de Los Dolores, se le piensa como la cuna de la revolución de independencia. Podríamos seguir con una lista numerosa de "cunas de la revolución" en distintos países.

Si esta tradición se ha sostenido a lo largo de las centurias es porque la remembranza constituye en sí misma un acto que contribuye a mantener vivos los elementos más activos y progresistas de una sociedad, al mismo tiempo que le sirve como un basamento de su propia identidad. 
En el caso de la Revolución Mexicana, un signo de su vitalidad es la honra que representa para diversas entidades y poblaciones de la República que se reclaman como cunas del movimiento armado. Ello acontece cuando los pueblos se reconocen a sí mismos en ciertas gestas históricas. Esta identificación no puede inventarse ni decretarse artificiosamente, porque tarde o temprano aflorará el hecho histórico tal cual. Como tampoco, a la larga es posible inventar héroes, ni cancelar o desvirtuar movimientos tan profundos como una revolución, por las razones que sean. Ello ha acontecido con la Revolución Mexicana, cuyo movimiento armado se inició en 1910. Muy a pesar de numerosos intentos venidos de círculos académicos, de instancias estatales, de ocultarla, restarle importancia o desfigurarla, ha permanecido vigente en la memoria colectiva, de allí que varios estados y poblaciones de la República consideran que poseen los títulos históricos para merecer el honor de ser consideradas cuna de la revolución.

\section{PRECURSORES DEL MOVIMIENTO ARMADO DE 1910}

En los estados de Sinaloa, Tlaxcala, Coahuila, Yucatán y Puebla, se produjeron diversos hechos de armas precursores del alzamiento armado de 1910, que han sido objeto de estudios especializados y son conocidos en los ámbitos históricos regionales sobre todo, pero también en el espacio nacional. ${ }^{2}$

La primera de las entidades que reclaman el título de "Cuna de la Revolución" es Yucatán, pues el 4 de junio de 1910 se produjo en su suelo la sublevación antirreeleccionista de Valladolid, ciudad ocupada por los rebeldes. La población sufrió el asedio de tropas gubernamentales, que la tomaron a sangre y fuego el día 9 del mismo mes causando varias decenas de muertos.

Simultáneamente al de la península, se realizó en Sinaloa el alzamiento encabezado por Gabriel Leyva, abogado y maestro rural involucrado en la lucha política que dirigía Francisco I. Madero. El

2 Uno de los más tempranos, por ejemplo, es el de Carlos R. Menéndez: "La primera chispa de la Revolución Mexicana (El movimiento de Valladolid en 1910). Estudio Histórico-crítico”, Mérida, Yucatán, Imprenta de la Revista de Yucatán, 1919. 
4 de junio, empuñó las armas y pudo derrotar a una fuerza oficial en Cabrera de Inzunza el día 8. Capturado dos días después sufrió la temida "Ley Fuga" a manos de los rurales. Por tal razón, en 1930 la Comisión de Historia de la Secretaría de Guerra y Marina lo declaró "Protomártir de la Revolución Mexicana".

En Zacatelco, Tlaxcala, el día 16 de septiembre de 1910, un numeroso grupo de simpatizantes de Francisco I. Madero llevó a cabo una concentración de protesta por el fraude electoral y enfrentó a las tropas enviadas en su contra desde la capital del estado y desde la ciudad de Puebla. Muchos murieron y otros fueron enviados a trabajos forzados a Quintana Roo.

En Puebla, el 18 de noviembre la policía sitió la casa de los hermanos Aquiles y Carmen Serdán, eminentes líderes antirreeleccionistas. Finalmente, la finca fue invadida y destrozada por las fuerzas oficiales, uno de cuyos agentes asesinó a Aquiles, cuando lo encontró refugiado e indefenso en una especie de pequeño sótano.

El 21 de noviembre un fuerte contingente de maderistas, dirigido por Guillermo Baca, atacó infructuosamente la ciudad de Parral y después se dispersó hacia la sierra. Pocos días después aquel destacado demócrata fue asesinado en circunstancias nunca esclarecidas. En otras regiones del país como La Laguna, igualmente hubo salidas de los pueblos o hechos de violencia contra las autoridades gobernantes, respondiendo al llamado del Plan de San Luis Potosí para que el domingo 20 de noviembre de 1910, a las seis de la tarde, los ciudadanos mexicanos tomaran las armas y depusieran a las autoridades.

Todos estos hechos de armas ocurrieron en 1910 y varios después de proclamado el Plan de San Luis Potosí. Sin embargo, ninguno de los alzamientos o actos de rebeldía tuvo continuidad inmediata. Sus protagonistas fueron muertos, apresados o dispersados. Algunos se incorporaron a la lucha armada en las semanas y meses siguientes.

No me he referido a rebeliones más lejanas en el tiempo cuyos efectos aún indirectamente trascendieron hasta 1910, sino a las ocurridas en el contexto del movimiento antirreeleccionista cuyo principal dirigente fue Francisco I. Madero. Intentar la búsqueda 
de los orígenes del movimiento armado de 1910 más atrás en el tiempo, es una diversa empresa intelectual que no entra en el propósito de este texto.

Consignado lo anterior, se mira que cada una de las entidades federativas enlistadas posee títulos para reclamar el estandarte de “cuna de la revolución”. Sin embargo, por estricta lógica, no puede haber varias de ellas, sino, aunque se trate de un merecimiento simbólico, solamente puede ser una. Entonces, debe establecerse un criterio sólido del cual pueda partirse. Este, según mi juicio, es determinar el lugar en donde comenzó la lucha armada y tuvo continuidad, es decir, el sitio en el que se encendió la llama revolucionaria y se conservó viva, de manera tal que provocó o sirvió de apoyo y ejemplo a otras insurrecciones. De otra manera, puede hablarse de precedentes o "chispas" como también se ha dicho, pero que por diversas razones esos actos de rebeldía armada fueron reprimidos o sofocados, las chispas no se transformaron en una llamarada duradera o permanente. Este criterio no alude a los méritos de los luchadores sociales y políticos que incluso sucumbieron por su ideal democrático e igualitario. Menos aún pretende disminuirlos.

Son estas las razones por las cuales debe buscarse la cuna de la revolución en el estado de Chihuahua, donde circunstancias de distinta índole hicieron que la chispa deviniera en llama que nunca pudo ser sofocada por el ejército y la policía porfiristas.

\section{LOS INICIOS DE LA REVOLUCIÓN EN CHIHUAHUA}

En el mes de noviembre de 1910 se produjeron varios alzamientos armados o conatos de ellos en muchos lugares del territorio nacional, especialmente en el estado de Chihuahua. Sin embargo, hay un hecho histórico sobre el cual no existe duda alguna: fue en esta entidad federativa en donde se inició y desarrolló el movimiento armado que puso fin a la dictadura con la toma de Ciudad Juárez el 10 de mayo de 1911. Así lo reconoció y puso en claro el mismo presidente Porfirio Díaz. A este movimiento y no a otro se refirió en su manifiesto del día 7 de mayo de 1911 al afirmar: 
La rebelión iniciada en Chihuahua en noviembre del año próximo pasado y que paulatinamente ha ido extendiéndose, hizo que el gobierno que presido acudiese, como era de su estricto deber, a combatir en el orden militar el movimiento armado. ${ }^{3}$

Ahora bien, hasta el año de 2003 se había considerado al pueblo de San Isidro, en el municipio de Guerrero, merecedor del título de "Cuna de la Revolución", porque sin ser sus vecinos los únicos en haberse insurreccionado, sí fue el movimiento que ellos iniciaron el 19 de noviembre el que mantuvo encendida la llama de la revolución, librando desde ese día un gran número de batallas en contra del ejército federal, sacrificando la vida de una alta proporción de sus jóvenes y ejerciendo un poder de convocatoria para unir a numerosos colectivos de otras regiones del estado. En torno de este grupo formado en los pueblos del distrito Guerrero, se formó en unos cuantos meses el Ejército Libertador bajo las banderas del Plan de San Luis Potosí, cuyas tropas pusieron sitio a la ciudad fronteriza y la rindieron.

En efecto, desde el año de 1944, al celebrarse el 34 aniversario de la Revolución Mexicana, se colocó en San Isidro la primera piedra de un monumento a sus iniciadores. Sobre este dato véase el artículo de Luis Vargas Piñeira, con el preciso título "Un Monumento al Fuego de la Revolución, en la Cuna de Esta. Hoy se pondrá la primera piedra en S. Isidro, lugar del primer brote en 1910". En 1961 acudió al pueblo el Presidente de la República Adolfo López Mateos, quien inauguró la obra comenzada 17 años antes, develando una gran placa con la leyenda: A LA MEMORIA

3 Manifiesto del Presidente de la República, General Porfirio Díaz, 7 de mayo de 1910. Fuentes diversas.

4 Luis Vargas Piñeira, notable educador y escritor (1881-1954). El autor hizo una detallada descripción de los hechos y consignó los nombres de los vecinos alzados. “...se conmemora en San Isidro de Orozco, Chihuahua, el 34o. Aniversario de la Revolución, cuya cuna fue aquel ignorado lugar y del que partió el movimiento democrático y de justicia social de 1910. ...aquel movimiento armado fue el único que se realizó en el día fijado por don Francisco I. Madero; el que nació serenamente calculado, llegó a la victoria y se extendió por el país como reguero de fuego, llevando a todos los ámbitos de la República su llama... Muchos ignoran quiénes eran aquéllas gentes serranas de 1910 y cómo se levantaron en armas...Vamos a hacer un pequeño resumen...el día... en que se inició la revolución maderista en San Isidro". 
DE QUIENES INICIARON EL MOVIMIENTO REVOLUCIONARIO DE 1910 Y ABRIERON PARA EL PUEBLO UNA ETAPA DE POSITIVO PROGRESO. NOVIEMBRE DE 1961. En otro bronce fueron incluidos los nombres de varios de los vecinos de San Isidro insurreccionados en 1910.

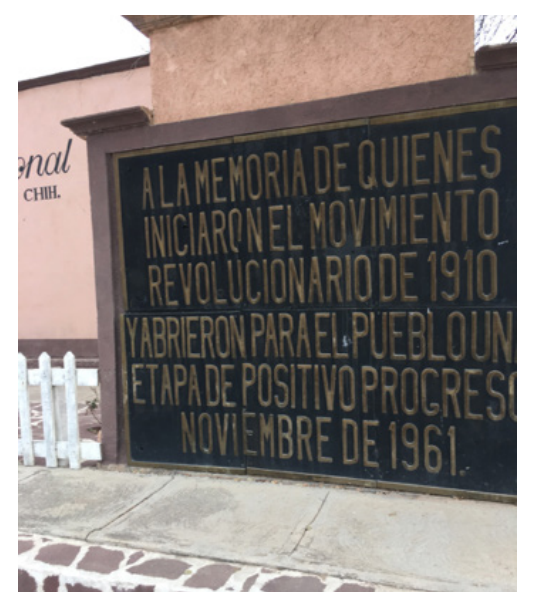

Pese a estos y a otros numerosos antecedentes, el 11 de noviembre de 2003 el Congreso del Estado de Chihuahua emitió un decreto en el cual se estableció oficialmente que la Cuna de la Revolución lo era el pueblo de Cuchillo Parado.

Para dilucidar la importante cuestión de nuestro pasado, sobre la cuna de la revolución y considerando al menos las dos versiones que sobre el tema se han difundido, es decir, si el movimiento armado de 1910 tuvo como foco el pueblo de San Isidro o el de Cuchillo Parado, es indispensable acudir sobre todo a las fuentes primarias y dejar que el material histórico hable por sí solo. En los párrafos que siguen he procurado reconstruir, paso a paso y con la mayor objetividad posible, el proceso de rebeldía que tuvo lugar en 1910, principalmente en el estado de Chihuahua, ateniéndome sobre todo a las fuentes originales y citando a los primeros autores que escribieron sobre la Revolución Mexicana. Previamente, como un tema que debe dilucidarse con antelación, analizaré el decreto del Congreso del Estado de Chihuahua que impuso una versión oficial. 


\section{EL CONGRESO DE CHIHUAHUA CAMBIA LA HISTORIA}

En decreto expedido por el Congreso el 11 de noviembre de 2003 y que tuvo fines de promoción turística, se decidió que la Cuna de la Revolución era el pueblo de Cuchillo Parado. La formal iniciativa fue presentada el 7 de octubre del mismo por los diputados Luis Raúl Valenzuela Colomo y Abelardo Valenzuela Olguín. En la exposición de motivos y antecedentes consignaron estos legisladores lo siguiente:

I. Cuchillo Parado, Cuna del movimiento revolucionario. En este pequeño poblado del desierto se inició el movimiento revolucionario de 1910 seis días antes que a nivel nacional. El 14 de noviembre a las 11 de la noche, Toribio Ortega, junto con 60 hombres, se levantó en armas para derrocar al cacique local, Ezequiel Montes, para luego cabalgar y realizar la toma de los poblados de Coyame y Ojinaga, en la frontera norte del país. Más adelante las fuerzas de Toribio Ortega se unieron a la división del norte bajo el nombre de brigada González Ortega, participando incluso en la toma de Zacatecas... CONSIDERACIONES... Segundo... que con la finalidad de fomentar el desarrollo turístico de la región de Cuchillo Parado y dar a conocer su trascendencia histórica, se hace necesario implementar programas turísticos, desarrollar campañas de difusión histórica de la entidad... Asimismo, es necesario que el poder ejecutivo genere la infraestructura necesaria para dar a Cuchillo Parado el sitial histórico que merece como auténtica cuna de la Revolución, no como una concesión graciosa, sino como un deber con la patria y con la historia.

Tercero

...que gracias a las gestiones llevadas a cabo por el expresidente de la Federación Fraternal Revolucionaria del estado de Chihuahua, Federico Zubiate Lares, y nieto de Ángeles Zubiate Lebario, uno de los 60 hombres de Toribio Ortega, quien murió en batalla en Gómez Palacio, Durango, es posible el presente trabajo.

Seguidamente la iniciativa comprendía varios puntos de acuerdo solicitando al Poder Ejecutivo diversas acciones para fomentar 
el desarrollo turístico como “... contratación de casas editoras, agencias especializadas en publicidad y cualquier otro medio de difusión y propaganda...”.

\section{Dictamen:}

A esta iniciativa recayó un dictamen por parte de la Comisión de Educación Pública, Cultura, Ciencia y Tecnología de fecha 11 de noviembre de 2003 en la cual sustancialmente se reprodujeron los antecedentes y consideraciones de la iniciativa de ley.

\section{Decreto:}

Conforme con el citado dictamen, el mismo día la sexagésima legislatura emitió el siguiente decreto:

ARTÍCULO PRIMERO.- Se declara Recinto Oficial del Honorable Congreso del Estado de Chihuahua, el Salón de Actos de Cuchillo Parado de la sección Municipal de Cuchillo Parado, Municipio de Coyame de Sotol, para celebrar sesión ordinaria a las 12 horas del día 14 de noviembre del año dos mil tres, con motivo de los actos conmemorativos, XCIII aniversario de la Revolución Mexicana.

Acuerdos y oficios:

El mismo día 11 de noviembre de 2003 se tomaron varios acuerdos y se giraron distintos oficios al gobernador del estado y dependencias del Ejecutivo, para que ejecutaran medidas de promoción turística en la región de Cuchillo Parado.

En los años sucesivos se han ratificado decretos parecidos al original de 2003.

Según se advierte, a la iniciativa presentada por los diputados no le antecedió ninguna consulta a historiadores o investigadores especializados en el tema, ni tampoco se cita en la exposición de motivos fuente alguna que acreditara las afirmaciones contenidas en el texto. Sirvió a los legisladores como única referencia el dicho del señor Federico Zubiate Lares, quien se dijo “...nieto de Angel Zubiate Lebario uno de los hombres de Toribio Ortega, quien murió en batalla en Gómez Palacio”. 
El dictamen que recayó a esta iniciativa se concretó a reproducir los conceptos de la misma, sin tampoco preocuparse por verificar dato alguno y lo mismo sucedió con el decreto de marras.

Por otra parte, la legislatura en turno pretendió alcanzar dos objetivos no necesariamente coincidentes como es el caso: promover el desarrollo turístico y dictando sin ningún sustento una versión de la historia regional y nacional. Este solo hecho le confiere al instrumento legislativo en análisis un vicio de origen.

La afirmación inicial contenida en la exposición de motivos y en el dictamen que dio lugar al decreto: "El 14 de noviembre a las 11 de la noche, Toribio Ortega, junto con 60 hombres, se levantó en armas para derrocar al cacique local, Ezequiel Montes, para luego cabalgar y realizar la toma de los poblados de Coyame y Ojinaga, en la frontera norte del país”, carece de todo fundamento, es decir, constituye un falacia, pues tales hechos nunca ocurrieron, ni el levantamiento en armas ni la toma de los poblados de Coyame y Ojinaga, los cuales permanecieron en poder del gobierno hasta después de la caída de Ciudad Juárez el 10 de mayo de 1911. Es decir, el decreto conforme al cual se declara al pueblo de Cuchillo Parado Cuna de la Revolución se apoya en una mentira.

La única manera de arribar a la verdad es examinando el material histórico idóneo, algo que nunca hicieron los legisladores de 2003. Por ello, pasemos a la siguiente fase de este análisis, es decir, a la exposición y examen del material documental a nuestro alcance, comenzando por las fuentes primarias y continuando con los primeros historiadores de la Revolución Mexicana, cuyos aportes han sido la base de estudios posteriores. 


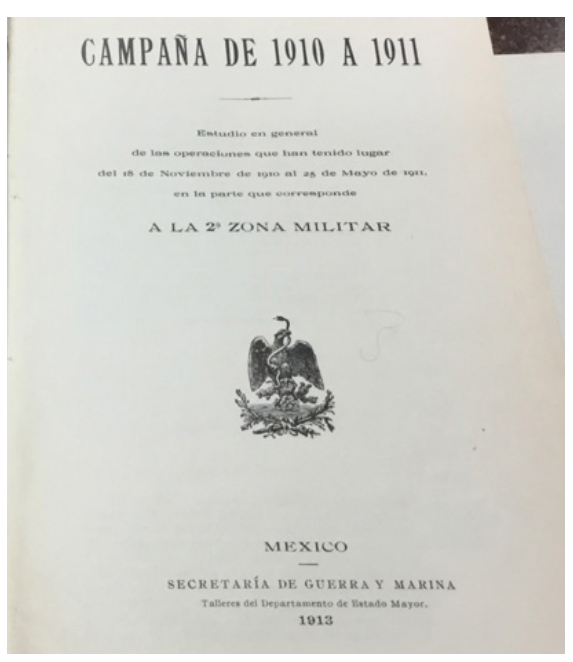

\section{PARTES MILITARES}

En el año de 1913 la Secretaría de Guerra y Marina publicó una amplia colección de documentos que contiene partes militares y consideraciones sobre la campaña de 1910 a $1911 .{ }^{5}$ El primer capítulo de este libro corresponde a los informes relacionados con hechos de armas y acontecimientos ocurridos en el mes de noviembre de 1910. En el sumario previo se consigna lo siguiente:

\section{Mes de noviembre}

Sumario

El 18 de noviembre se inicia el movimiento revolucionario en Ciudad Guerrero, donde un pequeño destacamento resiste hasta el 4 de diciembre.- El día 20 salen de Chihuahua dos compañías del $12^{\circ}$ Batallón para auxiliarlo; el 21 son atacadas en San Andrés, donde muere el teniente coronel Yépez, y el 27 sorprendidas en Pedernales, donde sucumbe el capitán Sánchez Pasos.- El 21 el teniente coronel Sardaneta dispersa a los sublevados de Gómez Palacio y el capitán Arnulfo Ortiz sale a perseguirlo. Algunas tropas marchan a proteger

5 Campaña de 1910 a 1911. México, Secretaría de Guerra y Marina, Talleres del Departamento del Estado Mayor, 1913. 
Hidalgo de Parral. El día 27 la columna Navarro abate a los sublevados en el rancho del "Rejón".

\section{Ataoue a Ciudad Guerrero}

Con relación al inicio del movimiento armado con el sitio de Ciudad Guerrero, el texto de referencia da cuenta que desde el 18 de diciembre de 1910 el capitán Salvador Ormachea comenzó a notar cierta excitación reveladora de un movimiento revolucionario de que le hablaban en dos cartas particulares el jefe de la zona y previniéndole que tomara las precauciones del caso. También que el día 19 salió a patrullar los pueblos y aprehendió al cabecilla Juan José González y cuatro sospechosos que guardaban armas y municiones; asimismo, que el día 20 apareció una columna de 200 "revoltosos" hacia Rancho Colorado dispersándose entre 20 y 30 hombres. Que a las primeras horas de la mañana del 21 comenzó el ataque por la espalda del cuartel, continuando los días 22 y 23 por parte de los sublevados crecido su número a 400. Los días 24 , 25 y 26 se suspendieron los fuegos porque los "revoltosos" se habían reducido a 200 ya que el resto se había dirigido a Pedernales para cortar el paso a las compañías del $12^{\circ}$ batallón. El día 1 de diciembre llegó una columna de 800 revolucionarios que intimó la rendición. Por lo cual el día 4 careciendo de víveres y municiones y ante el peligro de que fueran lanzadas bombas de dinamita hacia el cuartel y teniendo apenas 62 hombres contra 1200 sublevados se determinó capitular.

\section{Movimiento de tropas hacia GuerRero}

El segundo informe narra que el día 20 de noviembre la Secretaría de Guerra ordenó al jefe de la segunda zona destacar dos compañías del $12^{\circ}$ batallón, ubicado en la ciudad de Chihuahua, para auxiliar a Ciudad Guerrero con cuatro oficiales y 170 de tropa. El día 21, al llegar a la estación de San Andrés una partida de "revoltosos" parapetados en la misma estación, las casas cercanas y en montones de leña que se encontraban a uno y otro lado de la vía, inició fuego sobre el convoy. Aunque el tiroteo duró solo 20

6 Op. cit., pág. 1. 
minutos, el efecto de la sorpresa fue considerable, pues murieron el teniente coronel Yépez y varios soldados y otros quedaron gravemente heridos junto con algunos pasajeros del tren.

\section{Batalla de Pedernales}

El tercer informe menciona que el 27 de noviembre la columna que venía de Chihuahua, compuesta por 4 oficiales y 158 de tropa, pasó la noche en la Hacienda de Pedernales y que a las 5:30 de la mañana en los momentos que pasaba la primera lista del día, fue atacada intempestivamente por 300 revolucionarios que se encontraban en las casas y en una cerca de piedra a unos 150 metros del campamento. Que la nueva sorpresa desmoralizó a la tropa e introdujo el desorden en la misma. Que el comandante Sánchez Pasos subió a la azotea de una casa y allí fue muerto en los primeros disparos sucumbiendo también otros soldados. Que como a las 3:30 pm los revolucionarios aparecieron hacia los flancos y retaguardias de la línea de fuego, por lo cual el capitán Castillo se vio obligado a ordenar la retirada logrando llegar 28 sobrevivientes a la ciudad de Chihuahua después de una larga y penosa marcha.

\section{Rebeldes en Gómez Palacio y Lerdo}

El cuarto parte militar informa que el 21 de noviembre un grupo de "revoltosos" desalojó a la policía de Gómez Palacio y se apoderó del cuartel. Siendo combatidos por 20 soldados del $8^{\circ}$ regimiento al mando del coronel Enrique Sardaneta, quien los persiguió con dirección a la Ciudad Lerdo donde fueron puestos en fuga y dispersados después de causarles varias muertes.

\section{DiSPERSIÓN DE LOS REBELDES EN GÓMEZ Y LERDO}

El quinto parte de guerra refiere la persecución que se hizo a los sublevados en la zona de Gómez Palacio y Lerdo, dándoles alcance en el rancho de Sapiori, donde fueron puestos nuevamente en fuga reincorporándose la tropa a la guarnición de Torreón. 
MoviLiZACión de tRopas a PARRAL

El sexto parte de guerra informa del envío de 100 hombres de infantería por ferrocarril a Hidalgo de Parral en vista de noticias alarmantes sobre iniciación de desórdenes en esta población y en la de Jiménez. Se consignan también diversos movimientos de tropas del sur de estado y de la ciudad de Chihuahua hacia la zona de Guerrero, especialmente el desplazamiento del general Juan J. Navarro y del coronel Fernando Trucy Aubert, quienes se concentran en Jiménez.

\section{Encuentro en el Rejón y Tecolote}

Séptimo parte de guerra. Encuentro en el rancho del Rejón el día 27 de noviembre de 1910. Narra que habiendo salido ese día de la ciudad de Chihuahua una columna militar a las órdenes del general Juan J. Navarro rumbo a Ciudad Guerrero y antes de llegar a San Andrés se dispuso que 100 hombres a las órdenes del coronel Trucy Aubert regresaran a Chihuahua y que al pasar por el Cerro del Tecolote fue atacada por el enemigo, por lo cual el grueso de la fuerza acudió a su auxilio bajo el mando del general Navarro. El resultado fue de 15 muertos en las filas de los revolucionarios y 7 militares heridos.

En este mismo informe se da cuenta por primera vez del movimiento de tropas en la región de Ojinaga señalándose que el capitán primero Vicente Guillén con fuerzas del $3^{\circ}$ regimiento ocupó el 25 de marzo el pueblo "Cuchillo Parado" y el día 28 desde Ojinaga advirtió la presencia de "revoltosos" en las serranías. También la llegada de tropas a Guadalupe y Calvo y asimismo la salida de 100 soldados de Álamos, Sonora, rumbo a Chínipas, donde también se habían registrado movimientos de rebeldes.

\section{Mes de diciembre}

En el sumario de los acontecimientos relacionados con el movimiento revolucionario correspondientes al mes de diciembre se consignan: 


\section{Sumario}

Fuerza con que contaba la segunda zona en el mes de diciembre.Operaciones en los primeros días de diciembre por el coronel Joaquín Téllez en el sur de Chihuahua y norte de Durango.- Concentración de las columnas Navarro, Guzmán, Gordillo, Escudero y Luque en Pedernales y varios combates.- Encuentro en Cerro Prieto.- Encuentro de Pedernales y primero de Malpaso.- Se refuerzan las tropas que operan en el estado de Chihuahua y se les mandan municiones.- Tiroteo en el puente de Aldana.- Segundo encuentro de Malpaso.- El Coronel Emilio López es mandado a proteger el paso del convoy Guzmán por Malpaso.- Columna del coronel Gordillo Escudero que se encontraba en Torreón y que marchó a Chihuahua.- El Coronel Antonio Rabago marchaba con su regimiento a Chihuahua.- El general Ángeles García Peña marcha hacia Chihuahua y Pedernales.Movimiento del coronel Dorantes en la margen del Bravo rumbo hacia Ojinaga.- Encuentro en el rancho de Venegas.- Encuentro en el pueblo de Mulato.- El teniente coronel Cervantes marcha a Galeana y Casas Grandes.- Defensa y capitulación de Janos.- Marcha del teniente coronel Reynaldo Díaz de Guazapares a Batopilas.- Encuentro en los Alizos y la Yesca.- El teniente coronel Díaz obra en combinación con el Coronel Navarro.- La plaza de Ciudad Juárez.- Se refuerza su guarnición.- Marcha del segundo cuadro del regimiento.- Tiroteo en San Andrés.- Se destacan fuerzas en conservación del orden y persecución de levantados.- Total de refuerzos que recibe la zona. ${ }^{7}$

Movimiento en el norte de Durango y sur de Chihuahua

El día 2 de diciembre el General Juan A. Hernández releva en el mando de la segunda zona al general Manuel M. Plata contando con dos generales, 23 jefes, 98 oficiales y 1869 soldados.

El documento consigna que los primeros días del mes se producen movimientos de poca consideración en el norte del estado de Durango y en los distritos de Jiménez, Hidalgo y Mina de Chihuahua. Se refiere con ello a los producidos por grupos de rebeldes encabezados por Guillermo Baca y Pedro Gómez en el sur de Chihuahua, así como al de los vecinos de Santiago y Ocuila

7 Op. cit., pág. 18. 
en Durango que invadieron en la hacienda de Sombreretillos, así como otros en Villa Ocampo en Indé. Concluye diciendo que todas las partidas en estas zonas son dispersadas y que solo quedaban grupos pequeños de revolucionarios en las serranías.

Concentración de tropas PaRa COMbatiR a los ReVolucionarios de GueRRERO Y RECUPERAR LA CIUDAD

En los primeros días de diciembre salió de Chihuahua una fuerte columna comandada por el jefe de la zona general Juan J. Navarro compuesta por fuerzas de infantería, caballería y una sección de artillería de montaña, usada por primera vez en la campaña.

\section{Combate en Cerro Prieto}

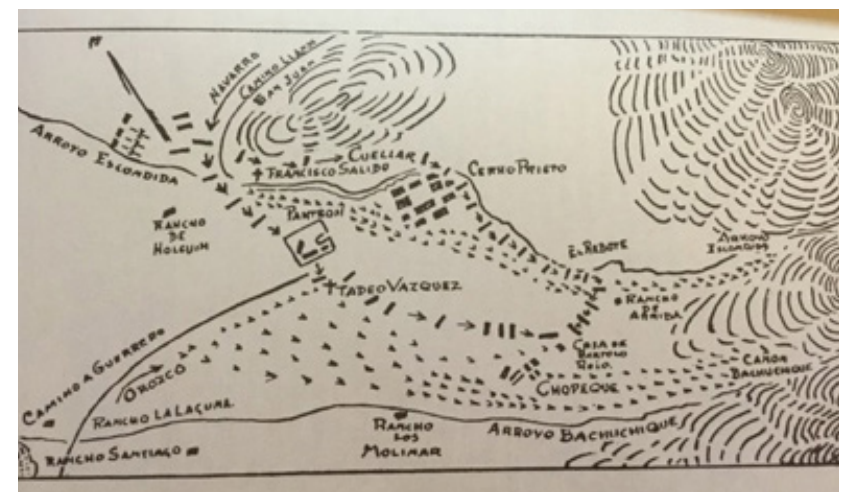

El 11 de diciembre se libró la más cruenta batalla entre las fuerzas revolucionarias y el ejército federal en el pueblo de Cerro Prieto. A raíz de este encuentro fue que la opinión pública nacional se dio cuenta de la relevancia que había tomado el movimiento revolucionario en Chihuahua, esto por la información publicada en los periódicos de la ciudad de México y acompañada por las primeras fotografías de revolucionarios y en particular de Pascual Orozco, para esas fechas nombrado ya jefe de las fuerzas revolucionarias en el estado por la junta de insurrectos reunida en Ciudad Guerrero el día 4 de diciembre. El parte militar que rindió el general Navarro dice que el número de rebeldes que lo 
atacaron era de 800 a mil hombres originarios de San Andrés, San Isidro, Ciudad Guerrero y ranchos de Santiago, mandados por los cabecillas Pascual Orozco, Epifanio Cos, Salido, Chacón y Vázquez Valdés. Hace enseguida un relato puntual con la disposición de las fuerzas y la actuación de su caballería, infantes y artilleros que hicieron 22 disparos contra el enemigo, que acallaron al cabo de hora y media el fuego del enemigo. Los revolucionarios fueron obligados a retirarse hacia el rancho de Chopeque haciéndose fuertes en sus casas y en el panteón de Cerro Prieto.

...desde donde opusieron tenaz resistencia hasta que atacados vigorosamente, fueron exterminados, quedando en el campo 80 muertos aproximadamente entre los cuales, según datos y apariencias, se cuentan tres cabecillas que se suponen sean Salido, Chacón y Vázquez Valdés; pero que no ha sido posible identificarlos... debe haber habido muchas bajas pues según informan vecinos de Cerro Prieto, durante la acción estuvieron pasando de huida por las calles del pueblo muchos heridos, en número de más de 50.

La batalla de Cerro Prieto constituyó la primera derrota de los insurrectos, que se enfrentaron a una unidad militar compuesta por las tres armas combinadas. Considerando los resultados, era de esperarse que allí hubiese concluido el movimiento revolucionario en la zona del distrito de Guerrero, tal y como ocurrió en otras regiones. Sin embargo, estos irredentos pueblerinos se crecieron ante la derrota, pues en lugar de capitular o retirarse a sus hogares, arreciaron la lucha, ahora con los terribles odios que propician las guerras civiles.

La columna triunfante de Navarro permaneció 4 días más en Cerro Prieto, en donde sus soldados cometieron varios crímenes en contra de vecinos pacíficos del pueblo. Antes, ya habían fusilado en el mismo lugar donde cayeron prisioneros varios revolucionarios, entre ellos el joven Alberto Orozco, tío de Pascual Orozco Vázquez.

Desde Pedernales, pueblo ubicado a la salida del cañón de Malpaso, Navarro destacó un cuerpo de caballería e infantería para apoderarse del desfiladero y proteger el convoy militar que en tren venía de la ciudad de Chihuahua en su auxilio. 
Encuentro en Pedernales y primero de Malpaso. Desplazamiento de TROPAS DE CHIHUAHUA HACIA GUERRERO

En el cañón de Malpaso se celebró un primer encuentro en el cual, según los militares, participaron 1500 rebeldes, quienes durante 6 horas de combate resistieron a las tropas federales. Al final dejaron en el campo 44 muertos a la vista. Los militares a su vez tuvieron 11 muertos y 29 heridos.

El 13 de diciembre la Secretaría de Guerra decidió reforzar las tropas que operaban en el estado de Chihuahua y ordenó que se embarcara para el estado el $6^{\circ}$ batallón a las órdenes del coronel Martín Luis Guzmán, cuerpo que estaba de guarnición en la ciudad de Querétaro. Llevando además 100 mil cartuchos para las tropas de Navarro. Después de vencer distintas dificultades por la carencia de trenes, estas tropas salieron finalmente el día 17 de diciembre de la ciudad de Chihuahua conduciendo además otros 150 mil cartuchos más la dotación del propio $6^{\circ}$ batallón.

\section{Tiroteo en el puente de Aldana cercano a San Andrés}

Como a un kilómetro de la estación Aldana, cercana a San Andrés, los trenes fueron atacados por una partida de rebeldes quienes hirieron a un sargento y a un soldado. Desde la estación de San Antonio el coronel Guzmán ordenó que una fuerza de caballería se adelantara al convoy marchando a ambos lados de las vías previendo algún ataque en el cercano cañón de Malpaso.

\section{SEgundo encuentro de Malpaso}

El 18 de diciembre en el camino de San Antonio a Casa Colorada el comandante ordenó que se hiciera fuego de artillería contra grupos de caballería que se advirtieron a lo lejos e igualmente ordenó una persecución por la caballería federal. Ocho kilómetros más adelante, en el cañón de Malpaso, los dos trenes que transportaban a las tropas y las municiones fueron atacados por los revolucionarios de frente y por los dos flancos, encontrándose los maderistas parapetados en los cerros que componen el cañón. La intensidad del fuego y las numerosas bajas que estaba sufriendo la caballería federal obligaron a una retirada. A las 4:30 de la tarde 
fue herido de gravedad el coronel Guzmán, jefe de la columna y más tarde el teniente coronel Vallejo, que era el segundo al mando. El parte militar dice que en el campo quedaron 20 muertos del enemigo y la tropa sufrió 18 caídos y 52 heridos, entre ellos los dos jefes ya mencionados y el mayor de ingenieros, Vito Alessio Robles y dos capitanes. Las bajas de los oficiales muestran, como en otras batallas, que los rebeldes tenían por táctica dirigir el fuego contra los mandos tal y como lo hacían los tomochitecos en 1892.

\section{Fracaso de LAS FUERZAS DE NAVARRO PARA APOyAR EL CONVOY DE Guzmán, su aislamiento en Pedernales}

De las tropas del general Navarro instaladas en Pedernales se envió una fuerte columna al mando del coronel Emilio López rumbo a Malpaso para proteger el convoy y abrirle el paso, sin embargo, fueron rechazados por los rebeldes posicionados en el cañón. No obstante la derrota de Cerro Prieto, la columna del general Navarro "estaba enteramente aislada por estar totalmente interrumpidas todas las comunicaciones, sin poder moverse por la mucha impedimenta que tenían, por los heridos...".

\section{Concentración de tropas Rumbo a Pedernales}

Ante las dificultades para desalojar a los rebeldes del cañón de Malpaso, la Secretaría de Guerra ordenó la salida hacia Chihuahua de nuevas tropas procedentes de Torreón, Monclova y la capital de la República, entre ellas una sección de ametralladoras, morteros y 300 mil cartuchos. Este nuevo contingente se puso al mando del general Luque.

\section{Reunión de tropas en SAn Antonio}

El día 25 de diciembre un contingente de mil hombres, al que se habían integrado además tropas provenientes de Guadalajara al mando del general Antonio Rábago, tardó tres días en cubrir los 25 kilómetros que distan Pedernales y San Antonio, pues debió rodear el cañón de Malpaso, para finalmente ponerse a las órdenes del general Navarro, quien se dispuso a retomar Ciudad Guerrero. 
Tercer combate de Malpaso

El 28 de diciembre de 1910 se libró un tercer y sangriento encuentro en cañón de Malpaso, que finalmente fue tomado por el ejército federal. El extenso parte de guerra rendido por el coronel Gordillo Escudero narra que los rebeldes resistieron encarnizadamente los ataques de la tropa, en una batalla que duró todo el día señalado. Es importante consignar que en el parte militar se destaca la participación del Sr. José Muñoz, jefe político de Cusihuiriachi, en auxilio del ejército. De igual manera, la baja de varios oficiales, blancos preferentes de los rebeldes.

\section{Nuevas tropas de México hacia Chinuahua}

El 31 de diciembre llegó a Chihuahua el general Ángel García Peña, al mando de tropas auxiliares y un tren sanitario.

Movimientos en la ReGión de Ojinaga

El día 6 de diciembre el capitán Vicente Guillén, que ocupaba Ojinaga con un pequeño destacamento, informa que 80 revolucionarios llegaron a Vado de Piedra y el día 10 tenía noticia de que se preparaban a atacar Ojinaga desde territorio norteamericano. Para hacer frente a esta amenaza se desplazó de Chihuahua a Ojinaga una columna compuesta por 321 soldados al mando del coronel Dorantes.

\section{PRIMER HECHO dE ARMAS EN LA ZONA DE OJinaGa}

El día 15 de diciembre tropas al mando del coronel Dorantes, recién llegado a Ojinaga, se desplazaron hacia el rancho de Venegas, donde entablaron en la tarde noche de ese día un tiroteo con un grupo de rebeldes a quienes dispersaron.

Según los informes del ejército federal, este fue el primer encuentro violento con rebeldes maderistas en la región de Cuchillo Parado-Coyame-Ojinaga.

Encuentro en Mulato y Cerro Chino

El 21 de diciembre se registró otro enfrentamiento en el pueblo de Mulato, ubicado a 33 kilómetros de Ojinaga, entre 107 soldados, 27 
guardas de la gendarmería fiscal y 11 voluntarios de Coyame contra un grupo de rebeldes, quienes según el parte militar contaban con la ventaja de poder pasar al lado americano a la vista de los "ranchers" (sic, del informe militar) del estado de Texas. Ante la incapacidad de las tropas para desalojarlos, se ordenó la retirada hacia el pueblo de Ojinaga.

\section{Marcha hacia Galeana y Casas Grandes}

El día 25 de diciembre el teniente coronel Cervantes llegó a Galena y el 26 a Casas Grandes, en virtud de haberse sabido que el día 22 había sido asaltado por los "revoltosos" un tren de pasajeros.

El día 28 el cabecilla Praxedis Guerrero, intimó rendición por teléfono a la autoridad política de Casas Grandes.

\section{DEFENSA Y CAPITULACIÓN DE JANOS}

El día 29 de diciembre a las 12 de la noche los rebeldes al mando de Praxedis Guerrero tomaron el pueblo de Janos y tuvieron dos muertos entre los que se contó el propio cabecilla Guerrero.

\section{Marcha de Guazapares a Batopilas}

El 24 de diciembre el teniente coronel Reynaldo Díaz al frente de 400 soldados recorrió los pueblos de Guazapares y Urique rumbo a Batopilas, por tener noticias de la existencia de grupos rebeldes.

\section{EnCUENTRO EN LOS Alizos y la YescA}

El día 30 de diciembre tropas del teniente coronel Díaz tuvieron una escaramuza en la cumbre de los Alizos.

\section{Tiroteo en SAN AndRÉs}

El 15 de diciembre el teniente coronel Agustín Martínez al mando del segundo cuadro de regimiento protagonizó un tiroteo cerca de San Andrés.

PERSECUCión DE REBELDES Y ENFRENTAMIENTOS EN EL NOROESTE

Cerca de la hacienda de San Diego fue perseguido y dispersado un grupo de rebeldes a las órdenes del licenciado Martín Casillas quien provenía de Ciudad Guerrero. 
CONCLUSiÓN DE LA CAMPAÑA DE 1910

Terminó así la campaña militar de 1910 según los informes del ejército federal, habiéndose reforzado en sus últimos días las tropas de la segunda zona con nuevas unidades provenientes de distintas guarniciones de la república. Según se puede advertir en este puntilloso y preciso recuento que hicieron los distintos oficiales que participaron en las operaciones militares, para el ejército mexicano el movimiento armado se inició con el ataque a Ciudad Guerrero poniendo como fecha de comienzo el 18 de noviembre porque ese día las autoridades advirtieron inquietudes y preparativos de los insurrectos. El domingo 20 de noviembre ya aparecieron grupos frente al pueblo y el asalto comenzó la madrugada del 21, prolongándose hasta el día 4 en que cayó la ciudad en poder de los maderistas, encabezados por Pascual Orozco Vázquez.

Por otra parte, no se registra ni se da cuenta de ningún alzamiento en el pueblo de Cuchillo Parado el 14 de noviembre de 1910, ni en las siguientes cuatro semanas. El primer hecho de armas en la extensa región donde se ubica el pueblo se produjo en el rancho de Venegas hasta el día 15 de diciembre. Por tanto, de esta inicial fuente primaria se puede confirmar que nunca ocurrió el alzamiento armado al que alude el decreto del Congreso de Chihuahua para establecer como Cuna de la Revolución al pueblo de Cuchillo Parado.

\section{PERIÓDICO EL CORREO}

En el alcance al número 3718 del periódico El Correo, publicado entre el 20 y 25 de noviembre de 1910 se da cuenta de algunos de los hechos armados con los que se inició la revolución. Como es de suponerse, los informes recibidos en la redacción de este diario publicado en la ciudad de Chihuahua eran todavía muy vagos. Sin embargo, se habla que están bajo ataque o han caído a mano de los revolucionarios Ciudad Guerrero, Miñaca, San Isidro y probablemente Temósachi.

También se informaba sobre el ataque de los maderistas a Lerdo y Gómez Palacio, así como su dispersión por las tropas federales. 
En una nota titulada "Por Ojinaga y 25 de marzo" se decía: "La situación en estos puntos parece ser algo delicada, no obteniendo aún detalles ciertos, pues las fuerzas levantadas han ininterrumpido las comunicaciones rompiendo los hilos telegráficos".

Lo mismo se informa de las comunicaciones de Chihuahua y Ciudad Juárez.

Otra nota denominada "De Guerrero y Miñaca" informaba: “... de estos puntos se asegura en público con visos de verdad, que fueron rudamente atacadas ayer durante día y noche quedando al poder de los revolucionarios y por consiguiente estando presas las autoridades del lugar".

En todos estos días el citado periódico da cuenta de los hechos al ataque a Ciudad Guerrero, a un tren en San Andrés, de movimientos de tropas hacia la sierra, aprestos de defensa en la ciudad de Chihuahua. De lo anterior se infiere que los únicos alzamientos armados que se registran en el mes de noviembre fueron los ocurridos en los sitios ya mencionados en los partes militares. Tan solo se informa de los rumores de gente armada en Coyame y Cuchillo Parado, sin asegurar que se trataba de rebeldes o de vecinos alistados para combatir posibles levantamientos.

\section{LOS TELEGRAMAS SOBRE EL MOVIMIENTO ARMADO EN CHIHUAHUA}

En 2010 el historiador chihuahuense Edelmiro Ponce de León Estrada publicó una colección de telegramas recibidos en la Secretaría General de Gobierno del Estado o enviados desde la misma, durante los primeros meses del movimiento armado. ${ }^{8}$ Tales comunicaciones provienen del archivo del eminente historiador José María Ponce de León. Para beneficio general, fueron rescatados por su editor y dados a la prensa. Se trata en consecuencia de fuentes primarias sobre la historia de la revolución en Chihuahua.

No es posible, por razones de espacio, reproducir estos telegramas provenientes de distintos lugares del Estado, de manera

8 Los hilos telegráficos en la revolución orozquista, Colección Editorial del Centenario, Chihuahua, Gobierno del Estado, 2010. 
tal que trataré de hacer una presentación de los mismos según la ciudad o pueblo de donde surgieron o a los cuales fueron dirigidos y de acuerdo con un orden cronológico.

\section{6 de noviembre. El Paso}

El primer telegrama está fechado en El Paso el día 16 de noviembre y lo firma "un mexicano que ama a su país". Contiene un aviso o prevención al Jefe Político de Juárez sobre la organización de revolucionarios que tratarán de tomar la ciudad fronteriza, para lo cual cuentan con la simpatía norteamericana. Tal denuncia confirma el hecho de que las autoridades mexicanas estaban bien informadas sobre los preparativos de la insurrección, mas aún cuando en el Plan de San Luis Potosí, con cierta ingenuidad, se señalaba el domingo 20 de noviembre a las seis de la tarde para que estallara el movimiento.

\section{9 de noviembre. Chihuahua a San Isidro}

Uno significativo es del día 19, el cual apunta en el mismo sentido, para ordenar al Jefe Político de Guerrero que: "Diga a Capitán Joaquín Chávez que arme cien hombres conservando 50 en San Isidro y enviando a Usted cincuenta.... Esta comunicación pone en claro que ya el gobierno tenía conocimiento o indicios del futuro alzamiento en San Isidro y de la magnitud que podría alcanzar, pues una guarnición de 50 hombres armados para un pequeño pueblo de menos de 1000 habitantes, es desmesurada, de acuerdo con las usuales en todo el país. Debemos recordar que el capitán Chávez era al mismo tiempo comandante de fuerzas rurales y uno de los hombres más ricos de la región, que había acaparado las tierras con las cuales se había dotado al pueblo de San Isidro. La orden fue tardía, pues como se sabe, ese mismo día comenzó la rebelión en dicha población.

\section{0 de noviembre}

Otras comunicaciones de ese mismo día, víspera de la fecha fijada por el plan maderista, previenen a diversas autoridades sobre posibles alzamientos. Uno dirigido a Enrique C. Creel, quien había 
dejado el cargo de gobernador en abril de 1910, cuando fue nombrado Secretario de Relaciones Exteriores en el gabinete porfirista y otro al jefe político de Chínipas del secretario general de gobierno ordenándole vigile a los antireeleccionistas.

\section{San Isidro y Guerrero}

El día 20, Enrique Chávez, uno de los hijos del capitán Joaquín Chávez, quien se encontraba en Chihuahua recibiendo atención médica, le informó en dos telegramas fechados en San Isidro: "El pueblo sublevado tomará Guerrero, estoy sin guardia. Anoche tomaron esta sin desgracias. Hoy todo pacífico. Informé a gobernador que hay 300 hombres con armas". "Entregué diez armas inferiores. No robaron. Escolta se fue a Arisiachi. Jefe de Armas Francisco Salido y Pascual Orozco, piensan tomar Ciudad Guerrero, deterioraron un zaguán. Andan 400 hombres armados y se espera que junten más gente...”. El mismo día 20, el capitán Francisco Antillón desde Miñaca envió un telegrama al gobernador informándole que: "Anoche se presentaron en mi casa 50 hombres que sacaron 'parque', pistolas y dinero y saquearon oficina de correos".

El mismo día se enviaron dos telegramas del jefe político, demandando que la fuerza en camino lleve 30 carabinas 30-30 para armar a los paisanos y anunciando el ataque inminente de los pronunciados.

Estos informes determinaron la salida inmediata de un contingente del ejército federal hacia Guerrero, según se desprende del telegrama que Guillermo Muñoz, jefe político de Cusihuiriáchi, quien en las siguientes semanas sería uno de los más eficaces auxiliares de las tropas del gobierno. Esta autoridad agradecía al gobernador, el mismo día 20, el aviso de esta medida y le pedía que le informara si las tropas que salieron para Guerrero “...iban por tren o por tierra".

Las anteriores comunicaciones muestran que las primeras acciones armadas de que se tuvo noticia, en concordancia con el Plan de San Luis Potosí, justamente el 20 de noviembre de 1910, fueron las tomas de San Isidro y Miñaca, ambas ocurridas la vís- 
pera, así como la aparición de los grupos armados en las afueras de Ciudad Guerrero, con miras a sitiar la plaza. ${ }^{9}$

\section{Coyame y Ojinaga}

El jefe municipal de Coyame, al jefe político del Distrito Iturbide, le menciona que: “...informes oficiales indican que se ignora el rumbo de los revoltosos pero dizque dijeron que se reuniría gente para atacar Ojinaga”. El mismo día 20, el jefe municipal de Ojinaga comunicó al jefe político de Chihuahua que: “...a cuatro leguas de aquí tenemos ciento y tantos revoltosos, quizá se resuelvan atacarnos esta noche".

Son estas las primeras comunicaciones de autoridades locales en las que se habla de "revoltosos" en la región de Ojinaga. Por estos dos telegramas sabemos que en esta zona fronteriza, donde se ubica el poblado de Cuchillo Parado o 25 de Marzo, había aparecido un grupo de rebeldes, sin que hasta el día 20 hubiesen intentado tomar alguno de los poblados o atacar a las fuerzas públicas. No hay todavía un alzamiento armado, sino vagas noticias de "revoltosos".

\section{Parral}

En esta ciudad, donde al día siguiente se realizara un ataque sangriento por los revolucionarios, el jefe político informa que no hay novedad. Sin embargo, horas después pide refuerzos pues “... grupos aumentan en número y escándalo”.

9 Si bien una nota del periódico El Correo de Chihuahua dio cuenta de que el 17 de noviembre fue atacada la hacienda de Chavarría, cercana a San Andrés, por un grupo mandado por Francisco Villa, es incierto si este asalto se realizó dentro los planes revolucionarios y con propósitos políticos, considerando que en los meses previos se produjeron múltiples eventos de este tipo, como el muy notorio perpetrado en la hacienda de Talamantes, poco antes. Villa fue señalado como autor o partícipe en varios de ellos. El periódico citado, el 21 de octubre de 1910 refería bajo un gran encabezado: "Son ya muy frecuentes los casos de robos y asesinatos en las haciendas que están poco defendidas". Algunos de dichos asaltos: al rancho propiedad de la señora viuda de Marcelo Guerra; rancho La Joya, propiedad de Jesús Payán; rancho San Isidro en San José del Sitio; rancho El Alférez, cercano a los límites con Durango, en Carretas y en Babonoyaba; en otro perteneciente a Francisco Martínez cercano a la frontera con Durango, en el Valle del Rosario, donde fue asaltado el mismo jefe municipal. 


\section{San Andrés}

J. E. Yslas, de San Andrés, informa al jefe político de Chihuahua:

No puedo organizar gente porque no tengo confianza y la mayor parte de la que tenía se ha ido huyendo... Continúa el rumor de que en "La Estacada" hay un número de hombres que se organiza para atacar este pueblo.

\section{1 de noviembre y días siguientes}

En este lapso se trasmite una gran cantidad de telegramas provenientes de los jefes políticos y muncipales, así como de particulares, provenientes de Guerrero, Cusihuiriáchi, Temósachi, Matachi, Parral, Batopilas. Otro grupo proviene de la ciudad de México, desde donde el secretario de Relaciones Exteriores, Enrique Creel, prácticamente ordena los movimientos del gobierno, así como las respuestas del gobernador José María Sánchez. El acervo es copioso y nos perderíamos en los detalles si se da cuenta de cada telegrama. En resumidas cuentas, los hechos, noticias e informes que en estos documentos se consignan son los siguientes:

El 21 de noviembre fue un día decisivo para orientar el rumbo que tomaría el movimiento revolucionario maderista en el estado de Chihuahua. En la madrugada comenzó el ataque a Ciudad Guerrero, por los alzados de San Isidro, encabezados por Albino Frías y Pascual Orozco, a los que se habían juntado ya los rebeldes de Pachera, dirigidos por Sóstenes Beltrán y los de Ranchos de Santiago, por Epifanio Coss. En los días subsecuentes llegarían las gentes de Bachíniva al mando de Luis A. García, de origen magonista y otros de Namiquipa. El prolongado ataque a Guerrero, que caería hasta el 4 de diciembre, se convirtió en una especie de rebelión local en contra de la élite política de la cabecera distrital, con la participación de vecinos llegados de prácticamente todos los pueblos. Río abajo, de la cabecera distrital, José de la Luz Blanco se apoderó de Santo Tomás, su pueblo natal, así como de Tejolócachi y amagó Matachi y Temósachi, según las comunicaciones de los jefes municipales.

Ese mismo día se produjo el ataque a Parral, que por la importancia de la población ocupó la atención de las autoridades 
federales. Los telegramas del jefe político Valles, eran angustiosos pidiendo ayuda. También el secretario Enrique Creel era presa de la ansiedad por el peligro que corría la ciudad, así que envió una comunicación urgente al gobernador, en la cual le señalaba la importancia de "levantar el espíritu parralense" para repeler el asalto, bajo la convicción de que cien hombres resueltos pueden resistir fácilmente a una "chusma de 300 bandoleros mal armados". Ofrecía que pronto llegarían los refuerzos federales e informaba que se habían abortado otros pronunciamientos en la república.

El ataque a la ciudad de Parral fue rechazado y los rebeldes dispersados. El día 22, el jefe político rindió un detallado informe en el que señala que hacia las 4 de la tarde del 21 se dominaba la situación. Agregó al día siguiente incluso los nombres de los principales rebeldes, entre ellos: Juan B. Baca, Guillermo Baca, Miguel Baca Ronquillo, Pedro Gómez y Atanasio Michel, jóvenes menores de treinta años, exceptuando el primero que frisaba los cincuenta.

Las noticias recibidas por la vía telegráfica de la región de Coyame consistieron en un telegrama enviado el día 22 en el cual el jefe municipal dice que "jefatura Ojinaga me dice que tuvo noticias que a las 2 de la tarde revoltosos se retiraron rumbo a San Antonio...". Y luego un enigmático: Con propio mandé original "25 de Marzo", refiriéndose quizá a algún documento.

Al día siguiente, el 23, la misma autoridad informó la llegada de las tropas federales y también que revoltosos se hicieron pasar como pacíficos, sin mencionar las circunstancias. Dos días después, el gobernador Sánchez comunicaba a Creel que "habían aparecido revoltosos en la región de Ojinaga”.

La última semana de noviembre es pródiga en comunicaciones. La llama arde y crece en Guerrero, de donde el jefe político informa que los revoltosos suspendieron los ataques a la ciudad, dejándola sitiada por una parte de sus fuerzas, mientras que con el resto se dirigieron a Pedernales, en donde consumaron la primera derrota a las fuerzas federales al acabar con la columna que se había enviado desde la capital para auxiliar a Guerrero. Con oportunidad, Urbano Zea advertía al gobernador que si Pedernales cae, Guerrero estaría perdido. Así sucedió. 
Cerca de Chihuahua, el ejército derrotó a una partida de revolucionarios que tuvieron la audacia de atacar a un destacamento de la columna dirigida por el general Navarro rumbo a Guerrero. La batalla de El Tecolote sirvió para animar a las fuerzas federales, aunque al ministro Creel "le parecieron pocos los muertos" que se hicieron a los rebeldes.

También llegaron noticias de la sierra, porque se vieron grupos de rebeldes en Témoris y existían temores de que hubiera en la vecina Chínipas. Todavía no se informa, sin embargo, de acciones de guerra.

\section{DICIEMBRE}

El mes comenzó con la noticia de la derrota de Pedernales y las condolencias del ministro Creel, quien días antes se había extrañado que Don Joaquín Chávez no hubiese levantado una fuerza capaz de combatir a los revolucionarios. Ignoraba que el viejo hombre fuerte de la zona además de encontrarse enfermo, había perdido su poder después de la insurrección del pueblo de San Isidro, donde residía y tenía la base de sus grandes negocios.

Las demandas de auxilio del jefe político Urbano Zea fueron en aumento; si la semana previa pensaba que con 300 soldados podía controlarse la situación, ahora clamaba por 1500 por lo menos, dado el crecimiento de los contingentes insurrectos. Finalmente, el día 4 de diciembre cayó Ciudad Guerrero y los rebeldes tuvieron algo que tanto temía el gobierno: la sede de un distrito, tan amplio y poblado como era el de Guerrero. Don Urbano Zea, antigua autoridad que había colaborado siempre con el gobierno en alzamientos previos como el de 1893 de Santo Tomás, explicaba el rendimiento y sus angustias:

Para conocimiento del Gobernador participo a usted que habiendo desertado el comandante Germán Espejo con el destacamento de sus órdenes del punto Santuario del Refugio y coincidiendo esto con el aumento de considerable número de Revoltosos, fue imposible toda resistencia, por cuya razón nos rendimos al señor Capitán del 
destacamento federal y yo con la condición de garantía de las vidas y nuestra libertad, entregando yo Jefatura Política y el señor Capitán armamento, caballos y municiones, siéndome honroso comunicar a usted que durante nuestra resistencia de 15 días mientras hubo aunque fuera una vaga esperanza de poder resistir, no escatimé el peligro de mi vida, la de mis dos hijos que estaban a mi lado- y la de poquísimos vecinos que me acompañaban, hechos que constan a todos los habitantes de esta ciudad sobre cuyo particular informaré ampliamente cuando las circunstancias me lo permitan.

Por el mensaje se entiende que la revolución crecía en la región como una marea y no había muchos dispuestos a enfrentarla. Para el 5 de diciembre las noticias de la caída de la importante población habían llegado a toda la sierra, según se desprende de un telegrama originado en Ocampo, en el cual J. M. Rentería informó al gobernador que "Jefe Político entregó a Pascual Orozco nombrado por los revoltosos”.

Conviene asentar aquí un hecho de gran relevancia para el conjunto del movimiento revolucionario en el país. El 6 de diciembre de 1910 se celebró en Ciudad Guerrero una junta revolucionaria en la cual participaron también los llegados de San Andrés, pueblo más cercano a la capital del estado, entre los cuales estaba Francisco Villa. La asamblea nombró como jefe de las armas a Pascual Orozco hijo, quien firmó ese día el primer manifiesto del movimiento armado nacional cerrándolo con el lema "Sufragio efectivo. No reelección”. Este acto tiene un gran significado histórico porque la revolución emprendida por estos campesinos (o labradores como se llamaban entonces), arrieros, mineros y pequeños comerciantes, se mostraba como una lucha organizada, portadora de ideales transformadores, contra la injusticia y los privilegios. No era la amorfa "chusma" como le llamaban despectivamente los voceros del gobierno de Díaz.

Este documento, de enorme relevancia por las razones expuestas, decía:

A las fuerzas republicanas maderistas en el Distrito de Guerrero, Chih., Méx., y a todos nuestros hermanos bajo la bandera de la 
Constitución de 1857 y demás leyes que de ella emanan. Sabed: que siendo tantos los atropellos y ultrajes que la tiranía oficial, llamada porfirista, ha venido desarrollando en todo el país con el mayor escándalo y cinismo, sin respeto a las leves, a la moral y a las buenas costumbres sociales; que para ese grupo de déspotas y tiranos, responsables únicos de cuantos males se originen a México, solo hay que oponerles la fuerza y esa fuerza caprichosa y cínica en que ellos se apoyan para sostener tanta injusticia; que nosotros aunque amamos la paz, no queremos la paz de los esclavos, puesto que, si estos no tienen libertad, tampoco tienen Patria; es por eso que hemos venido a tomar la última resolución cual es, repeler con la fuerza justa a esa brutal fuerza causa de tanto mal y de injusticia tanta que sobre nosotros pesa, siendo nuestra acción la observancia del mejor orden posible y llevar por lema, salvar a México de tanta ignominia, de tanta tiranía y de tantos abusos, para lo cual ocurrimos a la unión de todos los que seamos buenos mexicanos, verdaderos demócratas y republicanos leales. Sufragio Efectivo. No Reelección. C. Guerrero, diciembre 6 de 1910.

No solo se trató del primer manifiesto político del movimiento armado en el país, sino el único sostenido por un ejército, minúsculo todavía, pero capaz ya de desafiar a las fuerzas del gobierno en los campos de batalla, como ocurriría en los meses siguientes, sin dar ni recibir tregua.

Por su parte, el gobernador Alberto Terrazas, quien apenas había tomado posesión del cargo, urgía ahora al gobierno federal por el envío al menos de 2000 hombres para combatir a los maderistas de Guerrero y 250 dragones indispensables para pacificar de una vez por todas a la región de Parral. El día 6 de diciembre presentaba al Presidente de la República un panorama negro de la situación en el estado:

Están en poder de los revoltosos Guerrero y todo el ferrocarril de Chihuahua al Pacífico. Además, Cruces, Namiquipa, Temósachic, Satevó, Balleza, Carichic, Matachic, San Francisco de Borja, Témoris y Bachíniva, y hay síntomas de levantamiento en otros pueblos. 
Tengo fe en la ayuda que pueda usted impartirnos, confío en el patriotismo de los buenos ciudadanos y cuente usted con que sabré cumplir con mi deber.

De la región de Ojinaga no hubo novedades en esta primera semana del mes. El día 2, el jefe municipal de Coyame manifestaba que salieron revoltosos rumbo al Vado de Piedra, "dizque" para unirse a su jefe Lomelí, de quien se tenía noticia había llegado a Presidio acompañando a Abraham González. No hay todavía informes de acciones de guerra en la zona.

De Sonora había partido una fuerza federal que tomó Chínipas, con lo cual se estimaba que podía pacificarse toda la región serrana. Parece que las autoridades porfiristas se disputaban la intervención en las operaciones contra la insurrección, pues el vicepresidente Ramón Corral enviaba instrucciones el día 5 al gobernador para que esta fuerza se usara para perseguir a los revoltosos de Guazapares y evitar que los rebeldes de Guerrero se trasladaran a la sierra cuando fueran desalojados por la columna Navarro.

Por estas disposiciones se colige que en el gobierno federal no imaginaron que los insurrectos tomarían el camino del norte y que sus proyectos iban mucho más lejos de resistir en las serranías de la Tarahumara, pues se encaminaban nada menos que a tomar Ciudad Juárez.

En una confusa maniobra para conseguir la pacificación, el gobierno de Díaz autorizó al licenciado José María Gándara y al señor Amador González para que entablaran pláticas con los rebeldes de Guerrero, San Andrés y Santa Isabel, por ser el estado de Chihuahua "La única parte de la República que se encuentra ya en agitación”.

Ambos se dirigieron a San Isidro y luego a Guerrero. Desde el primer punto telegrafiaron el 3 de diciembre su regreso después de la imposibilidad de hablar con los jefes rebeldes. El día 7, igual desde San Isidro, C. Herrera comunicó que si el gobierno quiere hablar con ellos puede hacerlo directamente, entre tanto seguirían con las operaciones militares. 
En la sierra seguían las noticias de rebeldes que se encaminaban desde diversos puntos para engrosar a los rebeldes de Guerrero.

El ministro Creel seguía en comunicación constante con el gobernador del estado, pidiendo informes o bien anunciando la llegada de refuerzos. La apremiante situación hizo que fuera el propio presidente Díaz quien estableciera relaciones directas con las autoridades de Chihuahua. El día 7 comunicaba al gobernador Terrazas del envío de otros 400 soldados y antes de un refuerzo compuesto por ametralladoristas salido de Torreón.

La rebelión iniciada en el municipio de Guerrero había ya cundido a otras regiones, principalmente del noroeste, por los viejos contactos entre pueblos de la zona de Casas Grandes. Las noticias llegadas desde Galeana, Pearson y otros lugares eran alarmantes, pues se advertía el creciente número de rebeldes. La zona pronto quedaría incomunicada para las autoridades. Enrique Creel respondía a las llamadas de auxilio señalando que consideraba peligroso entregar armas a los oficiales de los pueblos por temor a que cayeran en manos de los alzados. Anunciaba un golpe definitivo de la columna Navarro contra los rebeldes de Guerrero para entonces poder limpiar de revoltosos toda la vía del ferrocarril hasta Ciudad Juárez.

En el sur del estado, no obstante la derrota y dispersión que sufrieron los maderistas en Parral el 21 de noviembre, seguía en pie de lucha la guerrilla encabezada por Guillermo Baca, pues el 6 de diciembre tomaron el poblado de Balleza, según informó el jefe político R. Valles.

La fuerte columna federal de Navarro, mientras tanto, avanzaba hacia Guerrero. Había abandonado los trenes para eludir el cañón de Malpaso rodeándolo y llegar así al distrito rebelde. Es la razón por la cual recibía continuos informes del J. Muñoz, el jefe político de Cusihuiriáchi, ubicado al otro lado de la sierra, quien se distinguió a lo largo de la campaña contra los maderistas por su eficaz colaboración con las tropas del ejército. El dia 6 telegrafiaba al gobernador diciéndole que había rebeldes en San Francisco de Borja, San Lorenzo y Carichi, pero que estaban esquivando a los 
soldados. Sin embargo, también le decía que tenía noticias de la coordinación de rebeldes de San Andrés, Pedernales y Guerrero, quienes estaban dispuestos a batirse con el ejército en algún lugar escogido por ellos. Con todo cuidado siguió la marcha de las tropas federales hacia Guerrero, recibiéndose informes en la oficina del gobernador de cada pueblo por el que pasaba y de los auxilios que recibían por las autoridades locales, como en Cusihuiriáchi, donde fueron alojados en las escuelas.

El objetivo militar oficial era dar un golpe demoledor a los rebeldes de Guerrero y luego limpiar de insurrectos el resto de las zona donde se había detectado su presencia. Esto es lo que expresaba el ministro Creel al gobernador:

...una vez que el general Navarro haya recibido el "parque" que lleva el coronel Luque, podrá dar un golpe violento al grupo de Guerrero y enseguida operar sobre el enemigo donde quiera que se encuentre, haciendo movimientos rápidos por ferrocarril a Chihuahua, Ciudad Juárez y donde se necesite el auxilio.

Este mismo propósito estratégico del gobierno fue advertido por José C. Valadez, prestigioso historiador de la revolución:

Pero no era tanto de estas guerrillas románticas de las cuales se preocupaba el gobierno. La secretaría de Guerra mandó en cambio, que fuese perseguido, hasta exterminarlo, el núcleo rebelde acaudillado por Pascual Orozco: y al efecto, ordenó la organización de una columna de las tres armas, para dar una batida formal a las partidas orozquistas que operaban a lo largo de los ferrocarriles Kansas y Noroeste; y la columna salió de la capital de Chihuahua al mando del general Juan J. Navarro. ${ }^{10}$

Por fin, el 11 de diciembre de 1910 en las lomas y llanos de Cerro Prieto y el Chopeque, del municipio de Cusihuiriáchi, se libró la esperada batalla entre el principal núcleo de los insurrectos

10 Valadés C. José, Historia general de la Revolución Mexicana, primera edición, 1963, nueva edición corregida y aumentada [1976], Editores Mexicanos Unidos, pág. 222.

Chinuahua Hoy, aÑo i6, Núm. I6 (ENERo-Diciembre, 2018) 
en todo el país y la poderosa columna dirigida por el general Juan J. Navarro. En la fuente que he estado siguiendo en el presente capítulo, los telegramas publicados por el historiador Edelmiro Ponce, desafortunadamente hay una interrupción en el flujo de comunicaciones recibidos en la secretaría general del gobierno de Chihuahua desde el 8 hasta el 24 de diciembre. Sin embargo, las informaciones y estudios que se han hecho de la batalla de Cerro Prieto han sido múltiples. Recojo aquí parte del reportaje publicado en el periódico El Imparcial de la Ciudad de México, el día 18 de diciembre de 1910, apenas una semana después. En la página completa dedicada por el periódico capitalino a la batalla, se publicaron por primera vez imágenes de los revolucionarios chihuahuenses. Fue así conocido Pascual Orozco, el dirigente principal, quien aparece al lado de Eliezer García y Luis A. García, insurrectos de Bachíniva. También se publicaron las imágenes de los primeros revolucionarios muertos.

\section{Las primeras imágenes de los insurrectos de Chihuahua}

Algunas de las noticias del cotidiano capitalino eran inexactas pero en lo sustancial verídicas. Los revolucionarios sufrieron una gran derrota que los desangró, sacrificando parte del núcleo de hombres con el cual se inició la revolución en San Isidro. "El descalabro sufrido por los rebeldes fue terrible y decisivo" rezaba uno de los encabezados, junto con el equivocado informe de la muerte de Pascual Orozco, quien comenzaba a perfilarse como el principal dirigente armado de la insurrección. Muy apenas salió ileso del episodio guerrero, perdió su caballo y su espada, alcanzando a salir en ancas y a toda carrera, según cuenta Heliodoro Olea. Esta batalla quedó en la memoria de la gente del Distrito Guerrero por mucho tiempo. En San Isidro, platicaban los viejos como llegaban algunos caballos sueltos y ensillados al pueblo, de donde inferían quienes eran los dueños muertos. Recuerdo que por los años sesentas, durante mis tiempos de estudiante, un anciano me contaba en los Ranchos de Santiago, "Yo ví llorar en este portón a Pascual Orozco, cuando le dijeron de todos los muertos en El Chopeque y en Cerro Prieto". 
Murieron en Cerro Prieto, en combate o fusilados después de que se les agotó el parque y fueron hechos prisioneros: Antonio Frías, Graciano Frías, Flavio y Eduardo Hermosillo hermanos, Laureano Herrera, José Caraveo, Joaquín González, Jesús Antonio González y José González, hermanos que integraban la banda de música de San Isidro, los hermanos Jesús y José Morales, Alberto Orozco, José María y Felícitas Márquez hermanos, Tadeo Vázquez, Francisco Salido, Hilario Díaz, Cruz Márquez, Ramón Solís, José Dozal, Ignacio Valenzuela y José Aragón, casi todos de San Isidro quienes formaron el núcleo inicial de la insurrección armada. El pequeño pueblo pagó así su inicial cuota de sangre para la revolución, quizá como ningún otro de la República. ${ }^{11}$

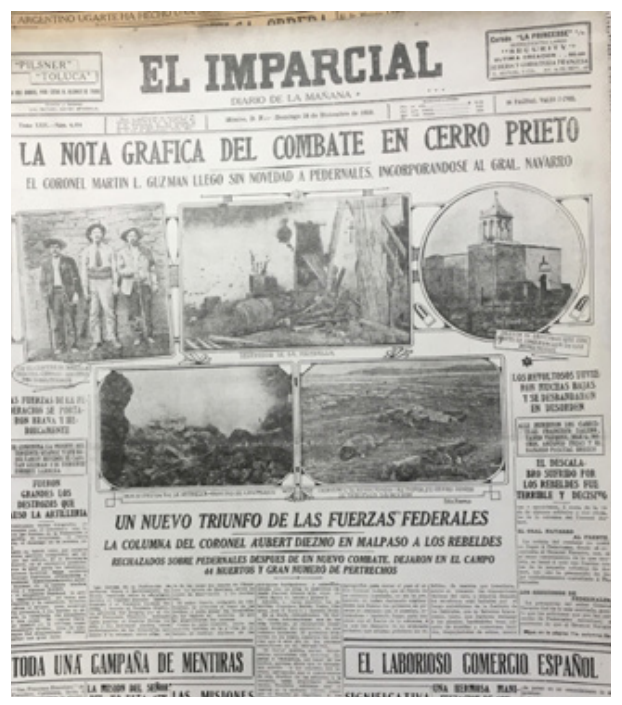

11 Véase, entre otras fuentes, que nombran a los caídos en Cerro Prieto a Juan Gualberto Amaya, Madero y los auténticos revolucionarios de 1910: hasta la Decena Trágica y fin del general Pascual Orozco, 1900-1913, primera edición, 1946, segunda edición [2010], Gobierno del Estado de Chihuahua. Heliodoro Olea, participante en la batalla escribió sobre este punto: “...en la falda del Cerro Prieto fue muerto por una granada el Capitán Francisco Salido y tres de sus compañeros, que con Tadeo Vázquez fueron treinta y dos, siendo tres de Bachíniva, dos de Namiquipa y los demás de San Isidro y ranchos adyacentes". Heliodoro Olea, Apuntes históricos de la revolución de 19101911: de Bachíniva a Ciudad Juárez, Chihuahua, 1961, pág. 37. La última descripción del combate de Cerro Prieto que conozco, es la de Reidezel Mendoza Soriano en Los rifleros de San Andrés, Gobierno del Estado de Chihuahua, 2011. El capítulo incluye una lista de nombres entre caídos, malheridos y sobrevivientes. 


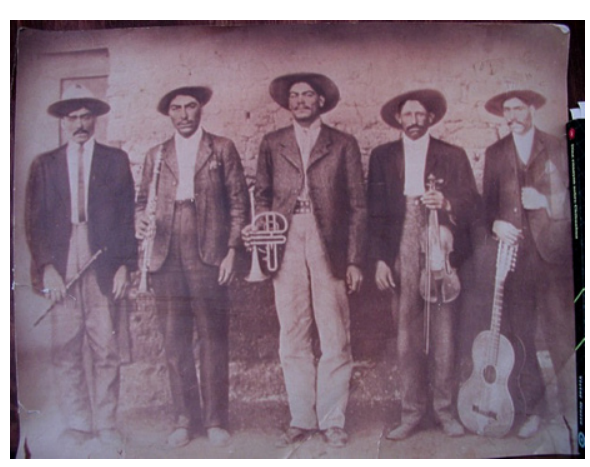

Los hermanos González: Fidel, Joaquín, Jesús Antonio, José y el quinto cuyo nombre ignoro. Integraban la banda de música de San Isidro, Guerrero, antes de 1910. Excepto Fidel, el primero, de izquierda a derecha, murieron en la batalla de Cerro Prieto librada el 11 de diciembre de ese año, junto con otros veinticinco jóvenes más, del mismo pueblo.

Debemos a la pluma previsora de un vecino de este pueblo, Emiliano Ordóñez una descripción del combate y de la masacre que perpetró el ejército federal en Cerro Prieto contra pacíficos vecinos del pueblo después de la batalla.

Por el texto de Ordóñez, escrito apenas una semana después, sabemos que las órdenes del general Díaz giradas al general Navarro, era la de llevar a cabo una matanza similar a la de Tomóchic, dieciocho años antes, pensando quizá en que un escarmiento de este calibre, bastaría para sembrar el terror y acabar con la rebeldía. Los soldados dispararon sobre la población civil sin parar en mientes de ancianos, mujeres y niños, asesinando a 22 de ellos. ${ }^{12}$

Lejos de alcanzar este propósito, los fusilamientos sin respetar las leyes de la guerra y el sacrificio de inocentes, atizaron el fuego en el alma de los rancheros chihuahuenses. Nada habría ya que los detuviera de allí en adelante.

Pascual Orozco se dolió ante la muerte de los suyos, como he narrado. Sin embargo, no se doblegó por el pesar y apenas logró reunir a los dispersos, se aprestó a nuevas batallas contra el ejército federal, concentrado ahora en la tarea de perseguir y exterminar a los insurrectos del Distrito de Guerrero.

12 La narración de Emiliano Ordóñez fue incluida por Serrano en su libro. 
No obstante el triunfo de Cerro Prieto, el general Navarro no se atrevió a continuar hasta Ciudad Guerrero, cuya recuperación era el objetivo estratégico. Marchó con su columna a Pedernales, pueblo ubicado a la entrada del Cañón de Malpaso, estimando que carecía de la fuerza suficiente para ir más adelante. En Pedernales fue continuamente asediado por los insurrectos bajo el mando de Orozco. Como ya se vio en los partes de guerra del ejército, se produjo el 28 de diciembre de 1910 la tercer batalla librada en el cañón de Malpaso.

\section{LA LLAMA QUE NO SE APAGA: LA INSURRECCIÓN \\ SE TRASLADA AL NORTE}

Fortalecido el general Navarro con tropas federales de refresco, continuó su marcha hacia Ciudad Guerrero, que ocupó sin resistencia por haberla evacuado los "liberales", como se conocía a los insurrectos en la zona. El proyecto militar del gobierno era dejar fuera de combate a este grupo encabezado por Pascual Orozco y luego ocupar toda la vía del ferrocarril hasta Ciudad Juárez, desarticulando o eliminando a los focos rebeldes que habían aparecido en los pueblos del Noroeste. Sin embargo, después de una breve estancia en la sierra, donde los insurrectos tenían sólidos contactos, operaron un movimiento imprevisto por el ejército, que pensaba confinarlos fuera de las regiones más pobladas. El objetivo de los revolucionarios era desgastar a las fuerzas del gobierno, alcanzar la frontera para proveerse de armas y brindar un puerto de entrada a México desde Estados Unidos al dirigente Francisco I. Madero.

Pronto aparecieron en el municipio de San Buenaventura donde libraron una batalla exitosa tomando la población, se enzarzaron en un feroz combate con tropas federales en la sierra de La Mojina, luego tomaron varios trenes en Estación Moctezuma y amagaron Ciudad Juárez, librando otro encuentro en Samalayuca y en Estación Bauche. El historiador y militar Juan Gualberto Amaya hizo un puntilloso recuento de estos combates protagonizados por insurrectos que tuvieron su origen en San Isidro. En total sumaron doce hasta los primeros días de febrero de 1911. 
Para este año habían aparecido grupos guerrilleros en diversos lugares de la república y también se habían sostenido sobre las armas los maderistas en la región de Ojinaga, cuya matriz había sido el pueblo de Cuchillo Parado. Los partes militares de este periodo son abundantes y de ellos se infiere la proliferación de grupos armados que desafiaron al ejército en buena parte de la geografía chihuahuense.

\section{PRIMEROS AUTORES DE LA REVOLUCIÓN}

Examino en primer término a dos autores que escribieron sendos libros en los que tocaron el tema de los inicios de la lucha armada en México y en Chihuahua, entre los años de 1910 y 1914.

\section{Tomás Serrano. Episodios de la Revolución en el estado de Chihuahua. Julio de $1911^{13}$}

El libro de este escritor y periodista es, hasta donde puedo saber, el primero escrito sobre la insurrección de 1910. Durante más de un siglo permaneció ignorado, salvo para muy pocos especialistas, hasta su recuperación y vuelto a publicar en 2015. Su autor, un periodista que laboraba en el periódico Paso del Norte, editado en la ciudad texana, reunió información fresca sobre los alzamientos maderistas antes de la batalla de Ciudad Juárez, librada los días 9 y 10 de mayo de 1911. Tuvo la oportunidad de entrevistar a muchos campesinos-soldados, a varios de sus dirigentes y construir breves semblanzas de los actores y líderes más destacados de la naciente revolución. Incluyó a los siguientes (en este orden): Francisco I. Madero, Pascual Orozco Vázquez, Abraham González, Braulio Hernández, José María Maytorena, Carlos E. Randall, Víctor M. Venegas, José María Pino Suárez, Venustiano Carranza, Gustavo A. Madero, Federico González Garza, Juan Sánchez Azcona y Alberto Fuentes. Eran, en ese momento, los personajes más notorios del movimiento revolucionario, de acuerdo con las

13 Tomás F. Serrano, Episodios de la revolución en el estado de Chihuahua, El Paso Texas, julio de 1911. Hay otro libro contemporáneo al de Serrano: Hacia la verdad. Episodios de la revolución, de Gonzalo G. Rivero, Biblioteca Chihuahuense, 2006, prólogo de Jesús Vargas Valdez, pero no toca el tema de los inicios. 
percepciones e indagaciones del periodista-historiador. El autor fue un testigo de primera mano y gracias a todas las circunstancias en que fue concebido y redactado, a su texto no se le puede acusar de tendencioso, pues en época tan temprana no afloraban todavía los caudillos, partidos, pleitos y confrontaciones que dividieron el campo revolucionario en los años siguientes.

A propósito de la Cuna de la Revolución, Serrano escribió:

Un heroico núcleo de serranos...sin vacilaciones y sin miedos empezaron la épica contienda a pesar de que en el resto de la nación había ahogado el movimiento la mano férrea de la dictadura. Ya robusta la revolución debido a la generosa sangre derramada en los campos de Chihuahua por la gente de Orozco, tomó cuerpo gigantesco y se extendió por toda la nación...si Orozco hubiera muerto en Cerro Prieto, o hubiera desistido de su empeño, la revolución habría muerto en su cuna. Orozco fue el alma de la revolución.

En la segunda parte de su libro, Serrano pasó revista a los principales enfrentamientos armados ocurridos entre los alzados maderistas y el ejército federal, que culminaron con la toma de Ciudad Juárez. Incluye las siguientes batallas: Ciudad Guerrero, Pedernales, levantamiento en Hidalgo del Parral, ataque al tren en San Andrés, Cerro del Tecolote, Cerro Prieto, desfiladeros de Malpaso, Bauche, Casas Grandes y Ciudad Juárez. No figuran todas, pero sí las más importantes de las batallas entre maderistas y tropas del gobierno, libradas hasta mayo de 1911.

Con referencia a Cuchillo Parado, Serrano consigna en su boceto biográfico de Abraham González, un dato relevante:

Como allí supo que la conspiración se había descubierto en Puebla y que se le buscaba empeñosamente en Chihuahua, y que las autoridades estaban en guardia, no siendo posible el golpe a Ciudad Juárez, optó por internarse al estado cruzando por territorio norteamericano a la ciudad de Ojinaga, donde se juntó a patriotas de Cuchillo Parado encabezados por el comandante Toribio Ortega (hoy, coronel), organizando allí una respetable columna que mucho 
contribuyó al buen éxito de la revolución, pues el gobierno federal se vio amagado a la vez en los dos extremos del estado; occidental y oriental...

Serrano no tiene la menor duda que el inicio de la lucha armada fue en San Isidro, del municipio de Guerrero, cuyo foco irradió sus efectos a toda la zona del noroeste chihuahuense hasta Ciudad Juárez. Al mismo tiempo, expresa otro hecho que corroboran las fuentes primarias y es que en la zona de Ojinaga y a partir del pueblo de Cuchillo Parado se formó otro núcleo maderista cuyo papel cobró relevancia como segundo frente, digámoslo así, para el ejército federal.

\section{Francisco de P. Ontiveros. Toribio Ortega y la Brigada González Ortega (1914) ${ }^{14}$}

De lo escrito por el mayor Ontiveros en este texto se ha derivado la versión sobre el supuesto alzamiento militar en Cuchillo Parado el 14 de noviembre de 1910. Es pertinente, por tal razón, reproducir íntegros los párrafos referentes:

La noche del 13 de noviembre, estando Ortega (Toribio) en su pueblo, tuvo conocimiento de que otro día iba a ser aprehendido por la autoridad del lugar, quien sospechaba que pretendía levantarse en armas. Sin pérdida de tiempo reúne a todos los adeptos a la causa y después de tener una larga conferencia acordaron desconocer otro día al gobierno lanzándose a la Revolución.

El 14 de noviembre de 1910, Toribio Ortega Ramírez, el patriota y abnegado ciudadano, al frente de sesenta hombres, en su mayoría desarmados, arrojó el guante del desafío a la cara del dictador y con las armas en la mano desconoció abiertamente a la usurpación.

Se lanzaba a la lucha sin ningunos elementos, teniendo por rival a un gobierno poderoso; pero él contaba con la justicia, y no midien-

14 Francisco de P. Ontiveros, Mayor, Jefe del Detalle de la Brigada Toribio Ortega, Chihuahua, 1914. Edición y reimpresión de Rosario Rodríguez Ramírez, Chihuahua, 2012. Antes de esta edición, se publicó en el año de 2003 el libro Toribio Ortega y la revolución en la región de Ojinaga, en la colección Biblioteca Chihuahuense del Gobierno del Estado, dirigida por Jesús Vargas Valdés, quien escribió un prólogo a la obra. 
do la talla y el valer de su enemigo, tenía entera fe en el triunfo. Si perecía en la lucha, ofrecería gustoso su existencia por su Patria. A propósito de la fecha del levantamiento, hago constar, por ser de justicia y rigurosamente histórico, que fue el primero que se levantó en armas en la República, contra el gobieno de Díaz, no fue Aquiles Serdán, ni mucho menos Orozco, puesto que ellos lo verificaron el 20 de noviembre en adelante. Nuestro biografiado fue como antes he dicho el primero, lo cual está plenamente comprobado por documentos que aún existen y que están debidamente autorizados por Don Abraham González. Si esto no ha sido público y notorio fue porque el ameritado General Ortega Ramírez, jamás quizo hacer de ello un reclamo ni adquirir popularidad por ese medio, dada la popularidad que lo caracterizó. La mañana del acontecimiento, Ezequiel Montes, el malvado e hipócrita cacique, poseído de un pánico indescriptible, huyó despavorido del pueblo. Estando algo caudaloso el río, lo pasó vestido y hubo quien lo viera en una labor cercana, lleno de lodo, sin sombrero y temblando de pavor. Esta es la virtud de las almas viles y miserables: la cobardía. Ortega pudo haberlo hecho prisionero, pero dotado de una alma generosa y magnánima, lo dejó ir, echando al olvido sus grandes villanías. Del pueblo dirigióse Ortega Ramírez con su gente a una sierra cercana que se llama El Pegüis, admiración causaría el contemplar aquella falange de hombres entusiastas, que no teniendo armas en sus manos, marchaban alegres y contentos para hacer una Revolución... De la sierra de El Pegüis se movilizaron a El Saucito. Las personas que los acompañaban entonces y que por siempre estuvieron a su lado hasta la hora de su muerte, Porfirio Ornelas, que fuera su segundo; Epitacio Villanueva, Marcelino Juárez y otros que hoy figuran en el Ejército Constitucionalista con categoría de jefes y oficiales... El 11 de diciembre de 1910, encontrándose en el rancho de Venegas, lugar distante siete leguas de Ojinaga y situado a las márgenes del río Bravo, tuvieron noticia de que el regimiento al mando del coronel Alberto Dorantes marchaba para atacarlos. Ortega Ramírez, de acuerdo con Don Abraham y con el coronel Perfecto Lomelí decidió esperarlos, posesionando su gente en unas lomas 
que están al oeste de la vía telegráfica... (sigue una descripción del tiroteo entre los rebeldes y las tropas federales). ${ }^{15}$

El ferviente relato que hace el mayor Ontiveros, pese a ser la base en la que se han apoyado los subsecuentes historiadores que han sostenido el alzamiento en armas en Cuchillo Parado, deja sin embargo muy claro que el 14 de noviembre lo que se produjo fue una salida del pueblo realizada por un grupo de vecinos que previsiblemente serían aprehendidos o al menos su dirigente Toribio Ortega Ramírez por sospechoso de rebeldía. En la descripción nunca se describe un combate, alzamiento armado, enfrentamiento o algún hecho similar. El cacique Ezequiel Montes, según parece, estaba solo y presa del pánico huye despavorido y los rebeldes ni siquiera toman el pueblo, sino que se dirigen de inmediato a la sierra de El Pegüis, seguramente con ánimo de organizarse y hacer acopio de armas. El primer encuentro armado, lo dice Ontiveros, tendrá lugar hasta el 11 de diciembre en el Rancho de Venegas. Aunque la fecha no coincide con las otras fuentes primarias que lo ubican el día 15, de cualquier manera, hasta ese momento no hay ningún informe de hechos de armas en Cuchillo Parado, ni en la zona donde se ubica. Menos una toma de Coyame, la cabecera municipal y de la ciudad de Ojinaga, como lo establece el decreto del Congreso que comentamos al inicio.

Ahora bien, es necesario hacer una crítica de esta fuente. Ontiveros escribió su relato en homenaje a quien fuera su jefe, el descatacado general de la División de Norte, por entonces en su momento de triunfo. Además de subordinado militar, fungió como secretario particular del general Ortega, hecho que puede explicar su insistente apología casi en cada párrafo del libro. Y lo hizo también cuando se habían suscitado las divisiones en las filas de los revolucionarios, que abrieron paso a los odios propios de las guerras civiles. En especial, creció la animadversión entre villistas y orozquistas o "colorados", por haberse estos primero alzado contra el gobierno del general Madero y haber decidido el futuro general Francisco Villa apoyar a este, después de haber sido re-

15 Op. cit., págs. 41 y 42. 
chazado por Orozco. Luego, lo más grave, porque Pascual Orozco suscribió un tratado con Victoriano Huerta, el asesino de Madero, y lo apoyó en el conflicto armado. Esto explica el énfasis que pone Ontiveros en su insistencia en que el levantamiento de Cuchillo Parado fue anterior al de Pascual Orozco, aunque ignora que en sus inicios este no era el principal jefe, sino Don Albino Frías. A diferencia del libro de Serrano, el de Ontiveros está marcado por estas intenciones políticas.

\section{Máximo Castillo, La Simple Historia de mi Vida, editada por Jesús Vargas, acompañada de un estudio introductorio, Chihuahua, 2009}

Las memorias de Máximo Castillo, quien falleció en 1919 y figuró entre los primeros alzados en el estado de Chihuahua en la región de la capital y el pueblo de San Andrés, son notables porque ofrecen información desconocida hasta la edición del libro citado. Castillo relata su involucramiento en el movimiento armado y menciona a sus principales actores. Se refiere a los rebeldes de San Andrés y a los del distrito de Guerrero, especialmente a Pascual Orozco. Es notable que en sus memorias no consigne ningún alzamiento armado en Cuchillo Parado o en la zona de Ojinaga, seguramente porque en su momento no tuvo noticia de ninguno de ellos, a pesar de estar al tanto de las acciones revolucionarias y de sus preparativos.

\section{OTROS AUTORES}

\section{Francisco R. Almada. La revolución en el estado de Chihuahua (1964)}

El eminente y respetado historiador Don Francisco R. Almada, repitió la versión de Ontiveros, sin consignar tampoco ningún hecho de armas, pues escribió en 1964:

En el pueblo de Cuchillo Parado, municipio de Coyame, Toribio Ortega, presidente del Club Antirreeleccionista se anticipó seis días a la fecha señalada para el levantamiento en virtud de haber recibido 
aviso de que el presidente seccional, Ezequiel Montes, trataba de aprehenderlo en unión de algunos de sus correligionarios. Frente a esta amenaza, procedió a reunir a sus adictos, acordaron desconocer al gobierno federal y, en número de sesenta, se lanzaron a la revolución en la mañana del día 14 de noviembre y se dirigieron a la sierra del Pegüis, con el propósito de completar sus preparativos. Mientras tanto Montes, presa del pánico, se dio a la fuga. ${ }^{16}$

Del levantamiento armado de San Isidro, Almada consigna:

A las 15:00 hs. del mismo 20 de noviembre, en número de ciento sesenta y cinco hombres armados, se dirigieron al Rancho del Conejo y nombraron primero y segundo jefes a don Albino Frías padre, y a Pascual Orozco hijo, respectivamente. Este había sido el puente de enlace de los antirreeleccionistas de San Isidro, Estación Sánchez, Témoris y Río Plata con el centro director de la ciudad de Chihuahua. Del expresado rancho dirigieron una nota a las autoridades de Ciudad Guerrero, pidiendo la entrega de la plaza. Esta estaba defendida por el Cap. Segundo Salvador Ormaechea con 2 oficiales y 62 soldados del 3er. Regimiento y el jefe político, Urbano Zea, con 43 hombres, entre empleados, policías y voluntarios, habiéndose apoyado la defensa en el cuartel, la iglesia, la jefatura, el santuario y otros puntos dominantes. El sitio de Ciudad Guerrero se inició el día 21. ${ }^{17}$

Antes, Almada explicó cómo aconteció la organización de la insurrección el día previo, con la toma de los pueblos de San Isidro y Miñaca.

\section{Benjamín Herrera Vargas. ¡Aquí Chihuahua!: cuna y chispa de la Revolución mexicana (1966) ${ }^{18}$}

Este autor publicó un libro en Ciudad Juárez, en el cual recogió documentos y testimonios de la revolución. Su conclusión sobre el tema fue la siguiente:

16 La revolución en el estado de Chihuahua, Biblioteca del Instituto Nacional de Estudios Históricos de la Revolución Mexicana, México, 1964, pág. 93.

17 Op. cit., pág. 94.

18 Edición del autor, Ciudad Juárez, 1966, pág. 168. 
Por eso, con toda justicia podemos decir sin temor a equivocarnos, que Cuchillo Parado, Chih., fue la "CHISPA DE LA REVOLUCIÓN MADERISTA" y "CUNA DE LA REVOLUCIÓN MADERISTA", fue San Isidro, Chih., en donde nacieron y se organizaron los mejores chihuahuenses, en torno al incomprendido Pascual Orozco. He allí la razón del título de mi libro.

\section{Juan Gualberto Amaya. Madero y los verdaderos revolucionarios de 1910: hasta la Decena Trágica y fin del general Pascual Orozco, 1900-1913 (1946) ${ }^{19}$}

Este autor es quizá quien trata con mayor puntualidad las campañas revolucionarias de 1910, desde el 19 de noviembre hasta el 10 de mayo de 1911. Ubica como origen del movimiento armado al pueblo de San Isidro, según lo he consignado páginas arriba.

\section{Marcelo Caraveo. Crónica de la revolución, 1910-1929 (1992)}

El autor es uno de los protagonistas del alzamiento armado en San Isidro, junto con sus hermanos Samuel y José, quien murió en la batalla de Cerro Prieto. Aunque el general Caraveo había concedido entrevistas a periodistas en las cuales se relataba su prolongada participación en la lucha armada, sus memorias se publicaron de manera póstuma hasta 1992. Contienen un austero testimonio del primer levantamiento armado en Chihuahua, que coincide con las fuentes primarias.

\section{Fernando Jordán. Crónica de un país bárbaro (1956) ${ }^{21}$}

Este libro del afamado periodista ha sido uno de los que con más fortuna ha corrido por el número de lectores. Constituye una narrativa histórica desde los primeros tiempos de Chihuahua hasta mediados del siglo XX. En cuanto a los comienzos de la revolución, consigna versiones hasta cierto punto contradictorias. En un párrafo dice: “El 'horrible despertar' fue el 20 de noviembre de 1910. Ese día en San Isidro, se encendió una hoguera de la Revo-

19 Op. cit.

20 Editorial Trillas, México, 1992, prólogo de Guillermo Porras, presentación de JeanPierre Bastian.

21 Centro Librero La Prensa, Chihuahua, séptima edición, 1978. 
lución, quizá con más fuerza que en ninguna otra parte del país" (pág. 315).

Más adelante, escribió:

Es el pueblo (Cuchillo Parado) donde, por circunstancias especiales se inició el movimiento armado de 1910. Seis días antes del grito de Orozco en la montaña, partió de aquí Toribio Ortega con toda la gente adulta del pueblo, rumbo al destino vago y sangriento de la Revolución (pág. 346).

Jordán no menciona en ninguno de los dos casos cómo ocurrieron los hechos y no sabemos a qué tipo de estos se refiere cuando habla del “...destino vago y sangriento de la Revolución”. Supongo que cuando afirma “...se encendió una hoguera” alude a la insurrección armada. Debemos tener en cuenta que su prosa es la de un escritor que ama la retórica y hace uso de ella a cada paso de sus trabajos. ${ }^{22}$

\section{SUMARIO DE HECHOS}

Este recuento histórico comprende los hechos de armas librados durante los meses de noviembre y diciembre de 1910, es decir, las fases iniciales del movimiento armado. Todas las fuentes primarias disponibles, corroboradas por los primeros autores de la revolución, revelan lo siguiente:

Las autoridades porfiristas tuvieron conocimiento de preparativos de levantamientos armados en aquellos lugares en donde existían clubes antirreeleccionistas. Dos de estos lugares fueron San Isidro, en el municipio de Guerrero, y Cuchillo Parado en el de Coyame.

Dispusieron establecer en San Isidro un fuerte contingente armado para prevenir un posible alzamiento, desde el 19 de no-

22 De otros historiadores he dado cuenta antes. No he mencionado a muchísimos de los modernos y contemporáneos porque no abordan en detalle estos comienzos. Hasta ahora, el estudio más extenso y documentado que conozco sobre la revolución en Chihuahua es el de Pedro Siller, Rebelión en la revolución: Chihuahua y la Revolución mexicana (1910-1915), Universidad Autónoma de Ciudad Juárez, 2017. 
viembre, sin embargo, la orden llegó tarde, pues ese mismo día se insurreccionó un grupo de vecinos.

El gobierno recibió informes inmediatos de este alzamiento y del ataque a la población de Miñaca ese mismo día.

También se informó de movimientos sospechosos en la región de Cuchillo Parado durante los días previos al 20 de noviembre, aunque ninguno se refiere a hechos de armas.

El ejército mexicano consigna como primer hecho de armas el ataque a Ciudad Guerrero, por los revolucionarios alzados en San Isidro, pueblo ubicado a 6 kilómetros de la cabecera distrital en la madrugada del 21 de noviembre, aunque los militares detectaron movimientos desde el día 18 de ese mes.

El ataque a Ciudad Guerrero, población de gran importancia estratégica militar y política, provocó una inmediata respuesta del ejército y movilizó un destacamento militar por tren desde la Ciudad de Chihuahua el mismo día 21 de noviembre. Este convoy a su vez fue atacado por los maderistas de San Andrés, "quienes estaban en comunicación con los del distrito Guerrero", a su paso por aquella estación, ubicada a unos cincuenta kilómetros de la capital del estado.

Entre el 19 de noviembre de 1910 y el 15 de diciembre del mismo mes, ocurrieron los siguientes encuentros armados: San Isidro, Miñaca, Guerrero, primero y segundo de Pedernales, primero, segundo y tercero del cañón de Malpaso, Cerro Prieto, San Andrés y el Tecolote. Salvo los dos últimos librados por maderistas de la región de San Andrés, todos fueron protagonizados por los rebeldes del distrito de Guerrero.

El primer encuentro armado de que se tiene noticia en la región de Cuchillo Parado, Coyame y Ojinaga, se libró en el rancho de Venegas, cercano a esta ciudad, el día 15 de diciembre de 1910. El segundo, de mayor importancia, tuvo lugar el 21 de diciembre en el poblado de El Mulato, cercano a Ojinaga.

El 29 de diciembre se registró una batalla en el pueblo de Janos, entre la guarnición federal y rebeldes pertenecientes al Partido Liberal Mexicano, resultando muerto su dirigente Práxedis G. Guerrero. 
El 30 de diciembre se produjo un tiroteo entre rebeldes de la zona de Batopilas con tropas federales llegadas del estado de Sonora. Otro, en un lugar cercano a San Andrés. Fueron los últimos hechos de armas del año de 1910.

\section{CONCLUSIONES GENERALES}

El punto de partida es un criterio histórico general, adoptado en diversos países sobre el origen de las revoluciones o insurrecciones, llamando cuna de estas al sitio en donde se produjo el hecho de armas inicial, el cual mantuvo su continuidad sin que sus protagonistas fuesen dispersados, encarcelados o exterminados, sino que pudieron seguir combatiendo y convocando a más adherentes a la causa.

Se registraron movimientos armados en varios estados de la república en el curso del segundo semestre de 1910, dentro del marco de la lucha antirreeleccionista. Ninguno de ellos tuvo continuidad en los siguientes meses. Fue en el estado de Chihuahua donde comenzó la insurrección armada contra la dictadura del general Porfirio Díaz y en donde prosperó, hasta provocar la renuncia del presidente de la república y abrir paso a la elección de Francisco I. Madero.

Fue el pueblo de San Isidro, en el municipio de Guerrero, Chihuahua, en donde se produjo el primer alzamiento armado y fue este núcleo el que mantuvo la flama de la insurrección, a costa del sacrificio de una buena parte de sus jóvenes, emitió el primer manifiesto del movimiento en el país y sirvió de centro para aglutinar o coordinar a otros grupos de rebeldes maderistas en diversos puntos del estado de Chihuahua.

Congruente con lo anterior, debe reconocerse en justicia a San Isidro, hoy Pascual Orozco, el título honorífico de ser la Cuna de la Revolución Mexicana. Este reconocimiento de ninguna manera implica desconocer el papel fundamental y heroico que jugaron vecinos de Cuchillo Parado en esta y sobre todo en las siguientes fases de la revolución. Pero los hechos son los hechos y el histo- 
riador, menos aun la autoridad, debe alterarlos o tergiversarlos por simpatías o antipatías políticas o de cualquier otra índole.

\section{BIBLIOGRAFÍA}

Almada, F. R. (1964). La revolución en el estado de Chihuahua, Biblioteca del Instituto Nacional de Estudios Históricos de la Revolución Mexicana, México.

Amaya, J. G. (2010). Madero y los auténticos revolucionarios de 1910: hasta la Decena Trágica y fin del general Pascual Orozco, 1900-1913, primera edición, 1946, segunda edición [2010], Gobierno del Estado de Chihuahua.

Caraveo, M. (1992). Crónica de la Revolución, 1910-1929, Editorial Trillas, México, prólogo de Guillermo Porras, presentación de Jean-Pierre Bastian.

Castillo, M. (2009). La simple historia de mi vida, editado por Jesús Vargas, acompañado de un estudio introductorio, Chihuahua, Gobierno del Estado, Biblioteca Chihuahuense.

Díaz, P. (1910). “Manifiesto del Presidente de la República”, General Porfirio Díaz, 7 de mayo. Fuentes diversas.

El Correo, alcance al número 3718, 20 al 25 de noviembre de 1910, noviembre 17 y octubre 21 de 1910.

Herrera Vargas, B. (1966). ¡Aquí Chihuahua!: cuna y chispa de la Revolución mexicana, edición del autor, Ciudad Juárez.

Jordán, F. (1978). Crónica de un País Bárbaro, Centro Librero La Prensa, séptima edición.

Mendoza Soriano, R. (2011). Los rifleros de San Andrés, Gobierno del Estado de Chihuahua.

Menéndez, C. R. (1919). "La primera chispa de la Revolución Mexicana (El movimiento de Valladolid en 1910). Estudio Históricocrítico", Mérida, Yucatán, Imprenta de la Revista de Yucatán.

Olea, H. (1961). Apuntes históricos de la revolución de 1910-1911: de Bachíniva a Ciudad Juárez, Chihuahua.

Ontiveros, F. (2012). Mayor, Jefe del Detalle de la Brigada Toribio Ortega, Chihuahua, 1914. Edición y reimpresión de Rosario Rodríguez Ramírez, Chihuahua. Antes de esta edición, se publicó 
en el año de 2003 el libro Toribio Ortega y la revolución en la región de Ojinaga, en la colección Biblioteca Chihuahuense del Gobierno del Estado, dirigida por Jesús Vargas Valdez.

Ordóñez, E. (1911). "La Batalla de Cerro Prieto", en Tomás F. Serrano, Episodios de la revolución en el estado de Chihuahua, El Paso, Texas.

Orozco, P. Jr. (s/f). Manifiesto "A las Fuerzas Republicanas en el Distrito Guerrero, Chihuahua., Méx. diciembre 6 de 1910”, varias ediciones.

Ponce de León, E. (2010). Los hilos telegráficos en la revolución orozquista, Colección Editorial del Centenario, Chihuahua, Gobierno del Estado.

Rivero, G. G. (2006). Hacia la verdad. Episodios de la revolución, Biblioteca Chihuahuense, prólogo de Jesús Vargas Valdez.

Secretaría de Guerra y Marina, Campaña de 1910 a 1911. México, Talleres del Departamento del Estado Mayor, 1913.

Serrano, T. F. (1911). Episodios de la revolución en el estado de Chihuahua, El Paso, Texas.

Siller, P. (2017). Rebelión en la Revolución, Chihuahua y la Revolución mexicana (1910-1915), Universidad Autónoma de Ciudad Juárez.

Valadez, J. C. (1976). Historia general de la Revolución Mexicana, primera edición, 1963, nueva edición corregida y aumentada [1976], Editores Mexicanos Unidos.

Vargas Piñeira, L. (1944). "Un Monumento al Fuego de la Revolución, en la Cuna de Esta. Hoy se pondrá la primera piedra en S. Isidro, lugar del primer brote en 1910”, Periódico Excélsior, noviembre 20 de 1944. 